\title{
Study of the Low-Temperature Reactivity of Large $n$-Alkanes through Cool Diffusion Flame Extinction
}

\author{
Christopher B. Reuter ${ }^{\mathrm{a},{ }^{*}}$, Minhyeok Lee ${ }^{\mathrm{a}, \mathrm{b}}$, Sang Hee Won ${ }^{\mathrm{a}, \mathrm{c}}$, Yiguang Ju ${ }^{\mathrm{a}}$ \\ ${ }^{a}$ Department of Mechanical and Aerospace Engineering, Princeton University, \\ Princeton, NJ 08544, USA \\ ${ }^{b}$ Department of Mechanical Engineering, University of Tokyo, \\ Hongo 7-3-1, Bunkyo-ku, Tokyo 113-8656, Japan \\ ${ }^{c}$ Department of Mechanical Engineering, University of South Carolina, \\ Columbia, SC 29208, USA
}

\author{
*Corresponding Author \\ Christopher B. Reuter \\ Department of Mechanical and Aerospace Engineering \\ Princeton University \\ Princeton, NJ 08544, USA \\ Phone: +1 6092581411 \\ Email: cbreuter@princeton.edu
}

Keywords: Cool flame, $n$-alkane, counterflow diffusion flame, extinction limit, low-temperature chemistry 


\title{
Study of the Low-Temperature Reactivity of Large $n$-Alkanes through Cool Diffusion Flame Extinction
}

\author{
Christopher B. Reuter ${ }^{\mathrm{a},{ }^{*}}$, Minhyeok Lee ${ }^{\mathrm{a}, \mathrm{b}}$, Sang Hee Won ${ }^{\mathrm{a}, \mathrm{c}}$, Yiguang Ju ${ }^{\mathrm{a}}$ \\ ${ }^{a}$ Department of Mechanical and Aerospace Engineering, Princeton University, \\ Princeton, NJ 08544, USA \\ ${ }^{b}$ Department of Mechanical Engineering, University of Tokyo, \\ Hongo 7-3-1, Bunkyo-ku, Tokyo 113-8656, Japan \\ ${ }^{c}$ Department of Mechanical Engineering, University of South Carolina, \\ Columbia, SC 29208, USA
}

\begin{abstract}
The low-temperature oxidation of hydrocarbon fuels has received increasing attention as advanced engines seek to operate in less conventional combustion regimes. Large $n$-alkanes are a notable component of many real transportation fuels and possess strong reactivity in this important low-temperature range. These $n$-alkanes have been studied extensively in various canonical kinetic experiments but seldom in systems with strong coupling between lowtemperature chemistry, transport, and heat release. To address this issue, the present study investigates self-sustaining $n$-alkane cool diffusion flames in a counterflow burner. The extinction limits of both hot diffusion flames and cool diffusion flames are measured at atmospheric pressure for a range of $n$-alkanes from $n$-heptane to $n$-tetradecane. It is observed that while these fuels behave similarly for hot flames, the larger $n$-alkanes are substantially more reactive in the low-temperature cool flame regime. Moreover, ozone addition strongly enhances the low-temperature chemistry to the point where the differences in fuel reactivity are nearly suppressed.

The experimental measurements are compared with numerical simulations employing both detailed and reduced chemical kinetic models of various sizes. Although the different kinetic models adequately predict the extinction limits of the hot flames, a large scatter is present in the model results for cool flames, and a general overprediction of the measured cool flame extinction limit is observed for all of the fuels studied. This implies that the cool flame heat release is not well agreed upon by the current chemical kinetic models, despite their capability to reproduce many homogeneous reactor experiments at low temperatures. Furthermore, it is observed that the cool flame heat release is spread over a substantial number of reactions involving large molecules, a trait that makes it particularly difficult to create reduced kinetic models that can accurately describe cool flame behavior. The results of this study suggest that the cool flame platform can provide crucial validation of the coupling between chemistry, transport, and heat release in flames at low temperatures.
\end{abstract}




\section{Introduction}

In the challenge to satisfy more stringent pollutant emissions standards and simultaneously design more efficient engines, combustion engineers have stressed the importance of finding clean combustion regimes in which reduced flame temperatures are prevalent $[1,2]$. Many promising engine technologies such as homogeneous charge compression ignition (HCCI) [3, 4], partially premixed compression ignition (PPCI) $[5,6]$, and reactivity controlled compression ignition (RCCI) [7, 8] take advantage of these windows of low pollutant emissions and high efficiency, but limitations in operating range and ignition timing have restricted their implementation. Ignition in such systems is often a complex, two-stage process [9] in which the heat release by the first stage, the cool flame, strongly affects the ignition timing of the second stage $[10,11]$. These low-temperature cool flames have also been shown to be an important influence on engine knock [12] and can extend the lean flammability limit [13-15]. Even in continuous combustion systems such as gas turbines, the low-temperature chemistry can significantly modify the fuel composition, which in turn may affect the turbulent burning velocity $[16,17]$ or stabilization mechanism $[18,19]$ of the main flame and possibly contribute to phenomena such as lean blow off [20]. As a result, the low-temperature oxidation of hydrocarbon fuels has received much attention over the years [21].

Particularly reactive at low temperatures are large $n$-alkanes, which make up a significant fraction of many real transportation fuels [22] and play an important role in the initiation of firststage ignition. For example, $n$-heptane is well known as a primary reference fuel component for gasoline and still makes its way into more complicated gasoline surrogate mixtures [23-25]. Recent investigations into both petroleum-derived and alternative jet fuel combustion have often utilized $n$-decane [26-28] or $n$-dodecane $[29,30]$ as a representative linear paraffin. Even heavier $n$-alkanes such as $n$-hexadecane are considered to be key surrogate components for diesel fuel $[31,32]$.

For the detailed study of $n$-alkane oxidation at both high and low temperatures, a variety of canonical experiments are traditionally called upon to validate chemical kinetic models. Flow reactors [33-37] and jet-stirred reactors [38-44] are commonly used for steady-state measurements of species concentrations, while shock tubes [40, 44-51] and rapid compression machines [33, 52-54] provide valuable ignition data as well as time-resolved speciation measurements. A great advantage of these types of experiments is that they can often be modeled under simple zero-dimensional and adiabatic assumptions. Much of the recent progress in developing detailed $n$-alkane chemical kinetic models [55-57] can be attributed to the wide range of conditions these canonical experiments are capable of reaching.

Despite these advantages, the aforementioned canonical kinetic experiments do possess some shortcomings. Low temperatures pose a problem for shock tubes [58] and rapid 
compression machines [59] due to lengthened ignition delay times and, consequently, a departure from adiabaticity, which is a critical assumption for kinetic interpretation. Continuous jet-stirred reactors and flow reactors do not have the same issues at low temperatures, but these experiments are typically heavily diluted [60], which means that the fuel oxidation and heat release are decoupled. Because of this decoupling, it is possible that chemical kinetic models derived from these zero-dimensional experiments may competently reproduce homogeneous reactor speciation data but at the same time struggle to predict phenomena such as flame speeds, which are strongly affected by the coupling between chemistry, transport, and heat release. To address this issue, complementary experiments including measurements of laminar flame speed [61-65] and counterflow flame extinction [62, 63, 66-68] are often relied upon to provide the necessary information about heat release and flame behavior in full-strength mixtures. However, these experiments have been widely limited to high-temperature flames.

Due to these current practices, an "experimental blind spot" is present in the study of low-temperature oxidation in systems with strong coupling between chemistry, heat release, and transport. However, an unexplored solution exists in the direct measurement of cool flames, which have been found in quasi-steady form under microgravity conditions [69-74] and in steady form under the assistance of ozone [14, 75-77]. Cool flames possess maximum flame temperatures of $600-1000 \mathrm{~K}$, a range commonly associated with the negative temperature coefficient (NTC) region of hydrocarbon oxidation [78]. Unlike their hot flame counterparts, cool flames are almost solely sustained by low-temperature reactions involving large fuel molecules. Therefore, experimental studies of cool flame behavior offer access to elusive information about the oxidation of full-strength mixtures at low temperatures, particularly in regards to the coupling with transport and heat release.

Motivated by this discussion, the present study is centered upon the measurement of the extinction limits of $n$-alkane/oxygen cool diffusion flames in a counterflow burner. The experiments are performed with and without ozone present in the oxidizer. This study seeks to examine whether large $n$-alkanes ( $n$-heptane through $n$-tetradecane), which have nearly identical reactivity in terms of their hot flame extinction [67], also possess similarity in their cool flame behavior. The capability of detailed and reduced kinetic models in predicting cool flame extinction is investigated as well.

\section{Experiment}

\subsection{Counterflow burner system}

The counterflow burner used in this investigation is identical to the one in several previous studies [14, 28, 29, 67, 75-77, 79-81] and is depicted in Fig. 1. The exit diameter of both the upper and lower burner nozzles is $1.3 \mathrm{~cm}$. For all measurements, the burner separation 
distance is set to $2.25 \mathrm{~cm}$, which allows for nearly ideal plug flow (less than $5 \%$ non-uniformity in the radial direction) [81]. A liquid fuel vaporization system consisting of a double concentric nozzle is incorporated into the upper burner. A syringe pump (Harvard Apparatus, PHD $22 / 2000$ ) feeds the fuel into the vaporization chamber, which is held at $550 \mathrm{~K}$. The prevaporized fuel/nitrogen mixture is then expelled out of the upper burner nozzle, which is maintained at a temperature of $550 \pm 5 \mathrm{~K}$ by PID control. All measurements are performed at atmospheric pressure.

Oxidizer is supplied to the lower burner after first passing through an ozone generator (Ozone Solutions, TG-20). When the ozone generator is turned on, the ozone concentration entering the lower burner can be determined as a function of the oxygen flow rate into the generator $[14,75-77,82]$. Although a variety of plasma species are produced by the dielectric barrier discharge, all of these species other than ozone have lifetimes less than $20 \mathrm{~ms}$ at $300 \mathrm{~K}$ and $1 \mathrm{~atm}[82]$.

As in previous studies involving this burner, the ozone concentration is defined as the mole fraction of ozone in the oxidizer stream exiting the lower burner. Fuel mass fraction $\left(Y_{F}\right)$ refers to the fuel $/ \mathrm{N}_{2}$ mixture exiting the upper burner. The strain rate $(a)$ is defined as the density-weighted gradient of the axial flow velocities [83].

Since the cool flames in this study are only dimly visible, planar laser-induced fluorescence (PLIF) of formaldehyde [84] is used to track the initiation and extinction of the cool flames more easily. A beam at a wavelength of $355 \mathrm{~nm}$ from an Nd:YAG laser (Quantel, Qsmart 850) is expanded into a vertical sheet and positioned along the centerline of the burner. An ICCD camera (Princeton Instruments, PI-MAX 4), stationed in front of the burner along with a band filter passing frequencies between 400 and $450 \mathrm{~nm}$, is used to capture the $\mathrm{CH}_{2} \mathrm{O}$ fluorescence. Due to the high $\mathrm{CH}_{2} \mathrm{O}$ concentrations in the cool flames, a laser energy of 200 $\mathrm{mJ} /$ pulse is easily sufficient. Numerical calculations (provided in the Supplementary Material) also show that there is a clear change in the maximum $\mathrm{CH}_{2} \mathrm{O}$ concentration between points before cool flame extinction (on the order of $1000 \mathrm{ppm}$ ) and after cool flame extinction (in the ppb range or less), indicating that $\mathrm{CH}_{2} \mathrm{O}$ PLIF is a suitable technique for tracking cool flame extinction..

\subsection{Numerical modeling}

Numerical calculations of flame extinction are performed using the OPPDIF [85] module of the CHEMKIN package with a plug flow assumption. A variety of detailed and reduced chemical kinetic models are tested. The detailed models include the Lawrence Livermore National Laboratory (LLNL) $n$-alkane model [86], the LLNL $n$-heptane model [24], and the National University of Ireland (NUI) $n$-heptane model [44]. Reduced models chosen from the 
literature include [87] and [88] for $n$-heptane (based upon [89] and [90], respectively) and [91], [92], and [93] for $n$-dodecane (based upon [86], [90], and [94], respectively). When necessary, the reduction of detailed models by the authors is performed using a path flux analysis (PFA) method [95]. For the cases with ozone addition, the ozone submodel is taken from Ombrello et al. [82] with the update from [96]. Additional details about the models employed can be found in Tables 1, 2, and 4 in the discussion below.

\section{Results and Discussion}

\subsection{Initiation of cool diffusion flames with and without ozone}

As discussed in previous papers $[13,14,75]$, one of the primary difficulties in establishing stable cool flames is finding conditions which sufficiently enhance the lowtemperature reactions that sustain the cool flame without also overly favoring the reactions that promote the transition to a hot flame. Ozone is particularly useful in this regard due to its tendency to release $\mathrm{O}$ radicals when it begins thermal decomposition near $450 \mathrm{~K}$. These $\mathrm{O}$ radicals have a strong effect on radical-starved cool flames, which typically have maximum $\mathrm{OH}$ concentrations of only a few ppm, but only slightly strengthen hot flames, which can possess radical pools of the order of a few percent. Therefore, for a window of strain rates and fuel loading around $a=35 \mathrm{~s}^{-1}$ and $Y_{F}=0.20$, isolated first-stage ignition of large $n$-alkanes can be achieved with ozone addition. The residence time is long enough to allow for the cool flame to be initiated, but it is also short enough to prevent the occurrence of second-stage ignition.

While continuous ozone addition produces self-sustaining $n$-alkane cool diffusion flames over a range of conditions [75] and provides for much cleaner boundary conditions than methods that directly introduce plasma species [97], it does slightly complicate the overall chemical kinetics [98]. The establishment of self-sustaining cool diffusion flames without ozone addition can be achieved, moreover, by simply increasing the fuel loading and then turning off the ozone generator, as seen in Fig. 2. At a fuel mass fraction of $Y_{F}=0.374$ and a strain rate of $a=68 \mathrm{~s}^{-1}$, the ozone-assisted $n$-dodecane cool flame in Fig. 2a can be converted into the ozone-less cool flame in Fig. 2b. While the ozone-less cool flame is approximately five times dimmer in terms of its chemiluminescence, it is fully self-sustaining under these conditions, and the ozoneassisted cool flame can be retained by turning on the ozone generator once again.

The ozone-less cool flame has much weaker chemiluminescence than its ozone-assisted counterpart, but it actually possesses a noticeably stronger $\mathrm{CH}_{2} \mathrm{O}$ planar laser-induced fluorescence (PLIF) signal, as shown in Fig. 3. The maximum centerline PLIF signal of the ozone-less cool flame in Fig. $3 \mathrm{~b}$ is $40 \%$ greater than that of the ozone-assisted cool flame in Fig. $3 \mathrm{a}$, a trend that is captured by modeling results. The model predictions [44] suggest that the small drop in $\mathrm{CH}_{2} \mathrm{O}$ concentration with ozone addition can largely be attributed to increased 
$\mathrm{CH}_{2} \mathrm{O}$ consumption through $\mathrm{CH}_{2} \mathrm{O}+\mathrm{O}=\mathrm{HCO}+\mathrm{OH}$. This reaction is responsible for $2 \%$ of $\mathrm{CH}_{2} \mathrm{O}$ consumption in the ozone-less cool flame but $26 \%$ in the ozone-assisted flame. Moreover, due to the relatively strong signal produced, the $\mathrm{CH}_{2} \mathrm{O}$ PLIF technique is used in this investigation as a more reliable method of tracking cool flame extinction than visual observation.

\subsection{Experimental measurement of cool diffusion flame extinction}

After initiating a cool diffusion flame, the cool flame extinction (CFE) limit can be measured by simultaneously increasing the $\mathrm{N}_{2}$ and $\mathrm{O}_{2}$ flow rates into the burner until the flame extinguishes and the PLIF signal disappears. This allows for momentum balance to be maintained as the strain rate is increased for a given flow rate of fuel. In this study, the measurements were repeated 2-3 times for each given fuel flow rate to achieve a consensus extinction strain rate. Typically, the experimental scatter remained within $\pm 3 \mathrm{~s}^{-1}$.

While the analysis of Won et al. [67] compared the extinction limits of $n$-alkane diffusion flames using a transport-weighted enthalpy (TWE) concept, the same idea cannot necessarily be applied here. The diffusion flames in [67] had air as the oxidizer, while this study uses $\mathrm{O}_{2}$ or $\mathrm{O}_{2} / \mathrm{O}_{3}$ mixtures. As a result, the flames in [67] were located on the oxidizer side of the stagnation plane, which means that the diffusivity of the fuel was a critical influence on the extinction limit (due the fact that it was necessary for the fuel molecules to diffuse across the stagnation plane in order to reach the flame). In this study, however, the flames (both hot and cool) are located on the fuel side of the stagnation plane, which means that many of the fuel molecules can simply be convected into the flame. Therefore, the use of TWE to compare the different $n$-alkane flames in this study would over-emphasize the influence of fuel diffusivity on the extinction limit. Consequently, the mass fraction $Y_{F}$ is instead used for cross-fuel comparisons. It can be seen in the Supplementary Material that effects of differences in fuel diffusivity among the $n$-alkanes studied are minimal compared to the effects of differences in low-temperature chemistry.

The extinction limits of ozone-assisted cool diffusion flames can be seen in Fig. 4 for five different large $n$-alkanes: $n$-heptane (nC7), $n$-octane (nC8), $n$-decane (nC10), $n$-dodecane (nC12), and $n$-tetradecane $(\mathrm{nC} 14)$. Since the ozone concentration in the oxidizer decreases as the oxidizer flow rate increases, it is impossible to maintain both momentum balance and constant ozone concentration. Therefore, the ozone percentage decreases with strain rate and is included as part of Fig. 4. It can be seen that these large $n$-alkanes possess similar CFE limits at low strain rates and high ozone concentrations. For example, at $Y_{F}=0.10$, all of the fuels tested extinguish within $\pm 5 \mathrm{~s}^{-1}$ of each other. However, a hierarchy becomes apparent at higher strain rates. At $Y_{F}$ $=0.18$, for example, the $n$-heptane cool diffusion flames reach CFE at a strain rate about $15 \%$ lower than the $n$-decane flames and $30 \%$ lower than the $n$-tetradecane flames, indicating that cool flame reactivity increases with $n$-alkane chain length under these conditions. 
This rise in cool flame reactivity with $n$-alkane size is even more apparent for the ozoneless flames in Fig. 5. The $n$-heptane cool diffusion flames extinguish at a mass fraction nearly double that of the $n$-tetradecane cool flames at the same strain rate. It should be noted that a higher degree of uncertainty exists for the $n$-heptane and $n$-octane ozone-less cool flames due to the enormous fuel loading $\left(Y_{F}>0.45\right)$ required to sustain these flames, which sometimes resulted in vaporization chamber temperature dropping to $525 \mathrm{~K}$ or even $500 \mathrm{~K}$. Despite this, the upper burner exit temperature remained within $10 \mathrm{~K}$ of the set value. In any case, it is unlikely that this increased uncertainty would affect the clear trend in cool flame extinction across fuels: larger $n$ alkanes produce stronger cool flames. It is also discernible, though less obvious, that the gap in CFE strain rate at the same $Y_{F}$ between $n$-tetradecane and $n$-dodecane $\left(\sim 20 \mathrm{~s}^{-1}\right)$ is smaller than the gap between $n$-dodecane and $n$-decane $\left(\sim 30 \mathrm{~s}^{-1}\right)$, which is still smaller than the gap between $n$ decane and $n$-octane $\left(\sim 45 \mathrm{~s}^{-1}\right)$. This implies that it may be fairly difficult to form self-sustaining ozone-less cool flames at atmospheric pressure for $n$-alkanes smaller than $n$-hexane or $n$-pentane.

While it is apparent from Figs. 4 and 5 that ozone greatly enhances the CFE limit, the precise effect of ozone on the low-temperature reactions governing cool flames is unclear. To answer this question, a rate constant sensitivity analysis has been performed for most affected fuel tested, $n$-heptane, which showed nearly an order of magnitude difference in $Y_{F}$ at CFE. The numerical comparison between near-limit ozone-assisted cool flames and near-limit ozone-less cool flames in Fig. 6 shows that the two are sensitive to the same reactions in more or less the same order, with the notable exception of the ozone decomposition reaction $\mathrm{O}_{3}+\mathrm{N}_{2}=\mathrm{O}_{2}+\mathrm{O}+$ $\mathrm{N}_{2}$. This reaction plays no part in the ozone-less flame but is responsible for $88 \%$ of the $\mathrm{O}$ radical production in the ozone-assisted flame. $57 \%$ of these $\mathrm{O}$ radicals then directly react with $n$-heptane itself $(\mathrm{RH})$ through $\mathrm{RH}+\mathrm{O}=\mathrm{R}+\mathrm{OH}$. Since direct fuel decomposition reactions (such as $\mathrm{C}_{7} \mathrm{H}_{16}=\mathrm{C}_{5} \mathrm{H}_{11}+\mathrm{C}_{2} \mathrm{H}_{5}$ ) are extremely uncommon at low temperatures due to the high activation energies required, the $\mathrm{RH}+\mathrm{O}$ reaction only competes with other fuel + radical $\mathrm{H}$ abstraction reactions. It appears, therefore, that primary effect of ozone addition is a boost to the initial breakdown of fuel into fuel radicals, which is one of the main impediments to the formation of self-sustaining cool flames [75].

\subsection{Numerical modeling of diffusion flame extinction limits}

In order to compare the experimental results for the different fuels to predictions using a single chemical kinetic model, the Lawrence Livermore National Laboratory (LLNL) detailed model [86] has been selected as a base. This model, composing 2755 species and 11173 reactions, describes both the low- and high-temperature oxidation of $n$-alkanes up to $n$-dodecane. Since a detailed model of this size is intractable for flame calculations, smaller models containing 130-150 species have been created for each fuel through a path flux analysis (PFA) method [95]. The path flux analyses have been performed using homogeneous reactor 
calculations over a range of temperatures $(600-1800 \mathrm{~K})$ at a pressure of $1 \mathrm{~atm}$. A summary of the reduced models can be seen in Table 1. For all results below, only ozone-less flames are investigated for kinetic simplicity and higher relevance to applied systems.

Figure 7 shows the comparison between the experimental measurements and model predictions for both hot and cool $n$-alkane flames without ozone addition. A semi-log plot is used due to the wide range in fuel mass fractions. A few observations are immediately apparent. First, the hot flame extinction (HFE) limits of the different $n$-alkanes lie much closer together than their CFE limits, a trend that is agreed upon by both experiments and modeling. This is in line with previous studies $[37,49,50,61,63,64,66-68]$ which have shown that large $n$-alkanes possess very similar oxidation behavior at high temperatures. Second, the reduced models slightly overpredict the HFE limits but generally remain within $10-15 \%$ of the experimental values. Finally, a tremendous disparity exists between the predicted CFE limits and the measured limits, which occur for fuel mass fractions nearly an order of magnitude higher. An investigation into what factors are behind such remarkable disagreement is contained below.

\subsection{Effects of model reduction on diffusion flame extinction limits}

Since the numerical simulations in Fig. 7 were carried out using a set of systematically reduced models, the effects of model reduction on the prediction of cool flame extinction limits can be investigated in a straightforward manner by comparing models of different sizes. Two detailed models for two different fuels are chosen as the base models for reduction. For $n$ dodecane, the LLNL $n$-alkane model [86] is retained from the above simulations. For $n$-heptane, the recently published NUI model [44] is used as the base model. This model contains updated thermochemistry and reaction rate rules (including pressure dependencies) compared to the older LLNL model. The different levels of reduction can be seen in Table 2. Reduced models are created for each fuel with $\sim 140$ species, $\sim 250$ species, $\sim 550$ species, and $\sim 1250$ species.

The effect of model reduction on the predicted extinction limits can be seen in Fig. 8a for $n$-dodecane and Fig. $8 \mathrm{~b}$ for $n$-heptane. The HFE limits for both fuels are shown to be nearly insensitive to the model size (less than a $5 \%$ shift in $Y_{F}$ ). This is somewhat expected since the PFA method has been demonstrated to reproduce hot flame behavior accurately for reductions below even 50 species [95]. Hot flames are dominated by high-temperature reactions involving small species, so as long as the distribution of intermediates (propene, ethylene, formaldehyde, etc.) is correct, the hot flame behavior can usually be predicted quite well [29].

On the other hand, the $n$-dodecane cool flames in Fig 8 a experience a $\pm 30 \%$ shift in $Y_{F}$ as various levels of model reduction are applied. The effect is somewhat scattered: the reduction from 1252 species to 582 species produces little change; further reduction to 289 species gives a less reactive solution (CFE limit shifts to the right); finally, the reduction to 145 species causes a 
large increase in cool flame reactivity. Even when considering the 1252-species solution, however, there remains a substantial discrepancy between the experiment and modeling results.

In Fig. 8b, the $n$-heptane cool flames display a consistent increase in reactivity as the model size decreases. In fact, it appears that the majority of the disparity between the 131species solution and the experiment can be attributed to the model reduction process. Even the conservatively reduced 526-species solution shows a clear departure from the detailed solution with the original 1268 species. The detailed solution itself, encouragingly, exhibits only a modest $30 \%$ difference in $Y_{F}$ from the experiment. While many factors surely contribute to the differences between the NUI and LLNL models, two may be particularly relevant for the prediction of cool flame extinction. First, the NUI model possesses updated thermochemistry, which likely leads to improved estimations of heat release rates and many net reaction rates. Additionally, the NUI model contains several reaction classes that are not present in the LLNL model such as olefinic hydroperoxyalkyl formation $\left(\mathrm{O}_{2} \mathrm{QOOH}=\mathrm{EROOH}+\mathrm{HO}_{2}\right)$, hydroperoxyl cyclic ether formation $(\mathrm{HOOPOOH}=\mathrm{CETH}-\mathrm{OOH}+\mathrm{OH})$, and the Waddington sequence (alkene $+\mathrm{OH}$ recombination). It may be that these reactions provide additional competition to the low-temperature degenerate chain-branching sequence, resulting in an overall reduction in the predicted cool flame reactivity and a closer agreement with the experimental measurements.

Since the PFA method relies on reaction path fluxes in homogeneous systems as its selection process, simulated ignition delay times at different model reduction levels are provided in Fig. 9a for $n$-dodecane and Fig. $9 \mathrm{~b}$ for $n$-heptane. The reduced models (generated using path fluxes over the range $600-1800 \mathrm{~K}$ at $1 \mathrm{~atm}$ ) perform best at high temperatures over $1000 \mathrm{~K}$, where the errors in ignition delay compared to the detailed solutions are never more than $20 \%$. The first-stage ignition delays are also fairly well-matched to the detailed models, with the exception of the 131-species $n$-heptane case. However, the total ignition delay times at low temperatures (less than $800 \mathrm{~K}$ ) are more difficult to predict with the reduced models. While the models with $500+$ species do a passable job, the 289 -species $n$-dodecane case and 131 -species $n$ heptane case show noticeable discrepancies, as they both double the total ignition delay time near $650 \mathrm{~K}$. It is interesting that the 131 -species NUI model, which overpredicted the reactivity of the cool flames compared to the detailed model in Fig. 8b, actually underpredicts the reactivity of the homogeneous mixtures. While this seems counterintuitive, it highlights the important distinction between homogeneous reactors (which are unaffected by transport processes) and flames (which possess strong coupling between chemistry and transport, particularly in terms of radical transport).

It appears from Figs. 8 and 9 that the simplification of the chemical pathways in the lowtemperature range is a significant challenge. An illustration of the complexity of lowtemperature chemistry is seen in Fig. 10, which depicts the distribution of net heat release for $n$ heptane hot flames and cool flames. The reaction size $\left(\mathrm{C}_{0}-\mathrm{C}_{8}\right)$ can be thought of as the size of 
the largest species participating in the reaction. For example, $\mathrm{C}_{7} \mathrm{H}_{16}+\mathrm{CH}_{3}=\mathrm{C}_{7} \mathrm{H}_{15}+\mathrm{CH}_{4}$ and $\mathrm{C}_{7} \mathrm{H}_{16}=\mathrm{C}_{4} \mathrm{H}_{9}+\mathrm{C}_{3} \mathrm{H}_{7}$ would be " $\mathrm{C}_{7}$ " reactions, while $\mathrm{OH}+\mathrm{HO}_{2}=\mathrm{H}_{2} \mathrm{O}+\mathrm{O}_{2}$ would be a " $\mathrm{C}_{0}$ " reaction. It is clear from Fig. 10a that heat release in the hot flame is primarily affected by reactions involving small species $\left(\mathrm{C}_{0}-\mathrm{C}_{2}\right)$. A few endothermic $\mathrm{C}_{7}$ reactions appear in the top heat consumption reactions, but even in the detailed solution these are essentially limited to the thermal decomposition reactions of $n$-heptane itself, heptyl radicals, and heptenes. For heat production in the hot flame, no reactions larger than $C_{3}$ are represented in the highest 70 reactions. Perhaps for this reason, the reduced solutions show excellent fidelity to the heat release rate distribution (and, as a result, excellent agreement for hot flame extinction).

A dramatically different story exists for the $n$-heptane cool flame in Fig. $10 \mathrm{~b}$, where $\mathrm{C}_{7}$ reactions are dominant and the reduced models are not nearly as well-matched to the detailed model. Examination of the detailed cool flame solution reveals that more than half of the top 100 reactions for both heat production and heat consumption involve $\mathrm{C}_{7}$ species. This includes not only the usual low-temperature chain-branching sequence $\left(\mathrm{RO}_{2}\right.$ isomerization, second $\mathrm{O}_{2}$ addition to QOOH, ketohydroperoxide formation, etc.) but also a rich variety of reactions including cyclic ether formation, $\mathrm{RO}$ decomposition, and $\mathrm{OH}$ addition to heptene (the Waddington mechanism [99]). Furthermore, the heat release is broadly distributed among these reactions, particularly in terms of heat consumption. While the top 10 heat consumption reactions in the detailed hot flame solution are responsible for $81 \%$ of the total heat consumption, the top 10 in the detailed cool flame solution only contribute $32 \%$ of the heat consumption. Table 3 shows how the most important reactions for cool flame heat release are not necessarily retained in the smaller models, even for the conservatively reduced 526-species model.

This may be one of the main reasons why the reduced models tend to overpredict the cool flame extinction limit, as seemingly obscure reaction classes such as RO decomposition, which are eliminated in the 131-species model due to their minimal impact on reaction path flux, make up a non-negligible portion of the heat consumption in the detailed solution. This broadened heat release behavior is nearly impossible to reproduce in the smaller models, as evidenced by the fact that the top 10 heat consumption reactions in the 131-species cool flame solution cause $73 \%$ of the total heat consumption. Further insight into the effects of the reduction process on the heat release rate is provided in the Supplementary Material.

\subsection{Predictions from reduced detailed and lumped models}

Kinetic model reduction is commonly applied to detailed models through techniques such as path flux analysis (PFA) [95] and direct relation graph (DRG) [100], but other ways of creating reasonably sized models for intensive computations are also available. One method is to use fully detailed models as a base to derive semi-detailed lumped models [56] in which the isomers of large molecules are grouped together (for example, simplifying the three heptene 
isomers into a general heptene species). These semi-detailed models can then be reduced appropriately [101]. Table 4 provides a survey of reduced $n$-dodecane and $n$-heptane models from the literature (as well as the 131-species NUI model from Table 2). Models based upon both detailed models and lumped models are included.

The predictions of extinction limits for $n$-dodecane flames and $n$-heptane flames can be seen in Figs. 11a and 11b, respectively. For both fuels, the difference in the HFE limit between the various models is small (as was the case for Fig. 8). For $n$-dodecane, the LLNL-based Luo model shows greatly increased cool flame reactivity compared to the other two models, as its $Y_{F}$ at CFE is approximately four times larger. The CRECK and UWisc models, both of which are reduced from larger lumped models, agree fairly well with each other and are within $40 \%$ of the experimental values. Comparatively, for $n$-heptane there are smaller but still noticeable differences among the predictions from $\mathrm{Ju}$ and NUI (which are reduced from detailed models) and the predictions from CRECK (based on a lumped model). Overall, it is clear that cool flame extinction is quite sensitive to the model employed. There is very little current consensus among the various chemical kinetic models concerning the behavior of cool diffusion flames at atmospheric pressure.

\section{Conclusion}

The capability of cool diffusion flames to remain self-sustaining without the assistance of ozone in a laboratory environment has been experimentally confirmed in a counterflow burner. The extinction limits of both hot and cool diffusion flames have been measured for large $n$ alkanes ranging from $n$-heptane to $n$-tetradecane. The hot flames of these fuels possess very similar extinction characteristics, which is consistent with previous studies. In terms of cool flame extinction, however, the chain length of the $n$-alkane has a significant effect on the cool flame reactivity: the larger $n$-alkanes produce substantially stronger cool diffusion flames than the smaller $n$-alkanes. These measurements indicate that the cool flame extinction limit is an effective target in evaluating low-temperature fuel reactivity. Moreover, it is found that when ozone-assisted cool flames are tested, the ozone dramatically enhances the low-temperature reactivity to the point where the cool flame reactivity becomes essentially independent of the size of the $n$-alkane, particularly at low strain rates.

Numerical simulations using both detailed and reduced chemical kinetic models of various sizes have been compared with the experimental extinction measurements for hot flames and cool flames. The model predictions for hot flames are consistent with each other and with the experimental data, but the cool flame calculations show wide scatter in the model results and a general overprediction of the measured cool flame reactivity. Reduced models, particularly those smaller than 200 species, are shown to have trouble reproducing the distribution of the cool flame heat release, which is spread over many reactions involving large molecules. These results 
suggest that chemical kinetic models which are derived from other canonical experiments may fail to predict cool flame behavior due to the complex coupling of low-temperature chemistry, transport, and heat release.

The present study has highlighted the usefulness of the cool flame platform in the study of low-temperature fuel oxidation and the measurement of low-temperature heat release in transport-affected systems. Just as laminar burning velocity experiments provide necessary flame data at higher temperatures, the direct measurement of cool flames can offer a valuable complement to other canonical kinetic experiments in the validation of chemical kinetic models at low temperatures.

\section{Acknowledgements}

This work is supported by NSF grant CBET-1507358, NASA ISS Post-Graduate award NNX15AB67G, and NASA microgravity grant NNX16AK07G. CBR is supported by the DoD National Defense Science and Engineering Graduate (NDSEG) Fellowship program. ML is supported through the Leading Graduate Schools Program, "Global Leader Program for Social Design and Management," by MEXT Japan. 


\section{References}

[1] S.W. Park, R.D. Reitz, Numerical study on the low emission window of homogeneous charge compression ignition diesel combustion, Combustion Science and Technology 179 (2007) 22792307.

[2] J.E. Dec, Advanced compression-ignition engines - understanding the in-cylinder processes, Proceedings of the Combustion Institute 32 (2009) 2727-2742.

[3] M. Yao, Z. Zheng, H. Liu, Progress and recent trends in homogeneous charge compression ignition (HCCI) engines, Progress in Energy and Combustion Science 35 (2009) 398-437.

[4] S. Saxena, I.D. Bedoya, Fundamental phenomena affecting low temperature combustion and HCCI engines, high load limits and strategies for extending these limits, Progress in Energy and Combustion Science 39 (2013) 457-488.

[5] S. Kimura, O. Aoki, H. Ogawa, S. Muranaka, Y. Enomoto, New Combustion Concept for Ultra-Clean and High-Efficiency Small DI Diesel Engines, SAE Technical Paper 1999-01-3681 (1999).

[6] M.P.B. Musculus, P.C. Miles, L.M. Pickett, Conceptual models for partially premixed lowtemperature diesel combustion, Progress in Energy and Combustion Science 39 (2013) 246-283.

[7] S.L. Kokjohn, R.M. Hanson, D.A. Splitter, R.D. Reitz, Fuel reactivity controlled compression ignition (RCCI): a pathway to controlled high-efficiency clean combustion, International Journal of Engine Research 12 (2011) 209-226.

[8] R.D. Reitz, G. Duraisamy, Review of high efficiency and clean reactivity controlled compression ignition (RCCI) combustion in internal combustion engines, Progress in Energy and Combustion Science 46 (2015) 12-71.

[9] C.K. Westbrook, Chemical kinetics of hydrocarbon ignition in practical combustion systems, Proceedings of the Combustion Institute 28 (2000) 1563-1577.

[10] S. Tanaka, F. Ayala, J.C. Keck, J.B. Heywood, Two-stage ignition in HCCI combustion and HCCI control by fuels and additives, Combustion and Flame 132 (2003) 219-239.

[11] H. Yamada, K. Suzaki, A. Tezaki, Y. Goto, Transition from cool flame to thermal flame in compression ignition process, Combustion and Flame 154 (2008) 248-258.

[12] P.R. Ballinger, P.R. Ryason, Isolated stable cool flames of hydrocarbons, Symposium (International) on Combustion 13 (1971) 271-277.

[13] Y. Ju, C.B. Reuter, S.H. Won, Numerical simulations of premixed cool flames of dimethyl ether/oxygen mixtures, Combustion and Flame 162 (2015) 3580-3588.

[14] C.B. Reuter, S.H. Won, Y. Ju, Experimental study of the dynamics and structure of selfsustaining premixed cool flames using a counterflow burner, Combustion and Flame 166 (2016) 125-132.

[15] Y. Ju, Numerical Simulations of Cool Flame Propagation Limits and Speeds at Elevated Pressures, 54th AIAA Aerospace Sciences Meeting, San Diego, CA, 2016.

[16] S.H. Won, B. Windom, B. Jiang, Y. Ju, The role of low temperature fuel chemistry on turbulent flame propagation, Combustion and Flame 161 (2014) 475-483.

[17] B. Windom, S.H. Won, C.B. Reuter, B. Jiang, Y. Ju, S. Hammack, T. Ombrello, C. Carter, Study of ignition chemistry on turbulent premixed flames of n-heptane/air by using a reactor assisted turbulent slot burner, Combustion and Flame 169 (2016) 19-29.

[18] A. Krisman, E.R. Hawkes, M. Talei, A. Bhagatwala, J.H. Chen, Polybrachial structures in dimethyl ether edge-flames at negative temperature coefficient conditions, Proceedings of the Combustion Institute 35 (2015) 999-1006. 
[19] S. Deng, P. Zhao, M.E. Mueller, C.K. Law, Stabilization of laminar nonpremixed DME/air coflow flames at elevated temperatures and pressures, Combustion and Flame 162 (2015) 4471 4478.

[20] M. Colket, S. Zeppieri, Z. Dai, D. Hautman, Fuel research at UTRC, Multi-Agency Coordinating Council for Combustion Research 5th Annual Fuel Research Meeting, Livermore, CA, 2012.

[21] F. Battin-Leclerc, Detailed chemical kinetic models for the low-temperature combustion of hydrocarbons with application to gasoline and diesel fuel surrogates, Progress in Energy and Combustion Science 34 (2008) 440-498.

[22] F.L. Dryer, Chemical kinetic and combustion characteristics of transportation fuels, Proceedings of the Combustion Institute 35 (2015) 117-144.

[23] D.B. Lenhert, D.L. Miller, N.P. Cernansky, K.G. Owens, The oxidation of a gasoline surrogate in the negative temperature coefficient region, Combustion and Flame 156 (2009) 549564.

[24] M. Mehl, W.J. Pitz, C.K. Westbrook, H.J. Curran, Kinetic modeling of gasoline surrogate components and mixtures under engine conditions, Proceedings of the Combustion Institute 33 (2011) 193-200.

[25] G. Kukkadapu, K. Kumar, C.-J. Sung, M. Mehl, W.J. Pitz, Autoignition of gasoline and its surrogates in a rapid compression machine, Proceedings of the Combustion Institute 34 (2013) 345-352.

[26] R.H. Natelson, M.S. Kurman, N.P. Cernansky, D.L. Miller, Experimental investigation of surrogates for jet and diesel fuels, Fuel 87 (2008) 2339-2342.

[27] S. Honnet, K. Seshadri, U. Niemann, N. Peters, A surrogate fuel for kerosene, Proceedings of the Combustion Institute 32 (2009) 485-492.

[28] S. Dooley, S.H. Won, M. Chaos, J. Heyne, Y. Ju, F.L. Dryer, K. Kumar, C.-J. Sung, H. Wang, M.A. Oehlschlaeger, R.J. Santoro, T.A. Litzinger, A jet fuel surrogate formulated by real fuel properties, Combustion and Flame 157 (2010) 2333-2339.

[29] S. Dooley, S.H. Won, J. Heyne, T.I. Farouk, Y. Ju, F.L. Dryer, K. Kumar, X. Hui, C.-J. Sung, H. Wang, M.A. Oehlschlaeger, V. Iyer, S. Iyer, T.A. Litzinger, R.J. Santoro, T.

Malewicki, K. Brezinsky, The experimental evaluation of a methodology for surrogate fuel formulation to emulate gas phase combustion kinetic phenomena, Combustion and Flame 159 (2012) 1444-1466.

[30] D. Kim, J. Martz, A. Violi, A surrogate for emulating the physical and chemical properties of conventional jet fuel, Combustion and Flame 161 (2014) 1489-1498.

[31] W.J. Pitz, C.J. Mueller, Recent progress in the development of diesel surrogate fuels, Progress in Energy and Combustion Science 37 (2011) 330-350.

[32] C.J. Mueller, W.J. Cannella, J.T. Bays, T.J. Bruno, K. DeFabio, H.D. Dettman, R.M.

Gieleciak, M.L. Huber, C.-B. Kweon, S.S. McConnell, W.J. Pitz, M.A. Ratcliff, Diesel surrogate fuels for engine testing and chemical-kinetic modeling: compositions and properties, Energy \& Fuels 30 (2016) 1445-1461.

[33] C.V. Callahan, T.J. Held, F.L. Dryer, R. Minetti, M. Ribaucour, L.R. Sochet, T. Faravelli, P. Gaffuri, E. Rani, Experimental data and kinetic modeling of primary reference fuel mixtures, Symposium (International) on Combustion 26 (1996) 739-746.

[34] A. Agosta, N.P. Cernansky, D.L. Miller, T. Faravelli, E. Ranzi, Reference components of jet fuels: kinetic modeling and experimental results, Experimental Thermal and Fluid Science 28 (2004) 701-708. 
[35] M.S. Kurman, R.H. Natelson, N.P. Cernansky, D.L. Miller, Speciation of the reaction intermediates from n-dodecane oxidation in the low temperature regime, Proceedings of the Combustion Institute 33 (2011) 159-166.

[36] S. Jahangirian, S. Dooley, F.M. Haas, F.L. Dryer, A detailed experimental and kinetic modeling study of n-decane oxidation at elevated pressures, Combustion and Flame 159 (2012) 30-43.

[37] P.S. Veloo, S. Dooley, S. Jahangirian, S.H. Won, F.L. Dryer, Low temperature oxidation of normal-alkanes, 9th U.S. National Combustion Meeting, Cincinnati, OH, 2015.

[38] P. Dagaut, M. Reuillon, M. Cathonnet, Experimental study of the oxidation of n-heptane in a jet stirred reactor from low to high temperature and pressures up to $40 \mathrm{~atm}$, Combustion and Flame 101 (1995) 132-140.

[39] J. Biet, M.H. Hakka, V. Warth, P.-A. Glaude, F. Battin-Leclerc, Experimental and modeling study of the low-temperature oxidation of large alkanes, Energy \& Fuels 22 (2008) 2258-2269. [40] B. Rotavera, P. Diévart, C. Togbé, P. Dagaut, E.L. Petersen, Oxidation kinetics of n-nonane: Measurements and modeling of ignition delay times and product concentrations, Proceedings of the Combustion Institute 33 (2011) 175-183.

[41] A. Mzé-Ahmed, K. Hadj-Ali, P. Dagaut, G. Dayma, Experimental and modeling study of the oxidation kinetics of n-undecane and n-dodecane in a jet-stirred reactor, Energy \& Fuels 26 (2012) 4253-4268.

[42] O. Herbinet, B. Husson, Z. Serinyel, M. Cord, V. Warth, R. Fournet, P.-A. Glaude, B. Sirjean, F. Battin-Leclerc, Z. Wang, M. Xie, Z. Cheng, F. Qi, Experimental and modeling investigation of the low-temperature oxidation of n-heptane, Combustion and Flame 159 (2012) 3455-3471.

[43] A. Mzé-Ahmed, P. Dagaut, G. Dayma, P. Diévart, K. Hadj-Ali, Experimental study of the oxidation of n-tetradecane in a jet-stirred reactor (JSR) and detailed chemical kinetic modeling, Combustion Science and Technology 186 (2014) 594-606.

[44] K. Zhang, C. Banyon, J. Bugler, H.J. Curran, A. Rodriguez, O. Herbinet, F. Battin-Leclerc, C. B'Chir, K.A. Heufer, An updated experimental and kinetic modeling study of n-heptane oxidation, Combustion and Flame 172 (2016) 116-135.

[45] H.K. Ciezki, G. Adomeit, Shock-tube investigation of self-ignition of n-heptane-air mixtures under engine relevant conditions, Combustion and Flame 93 (1993) 421-433.

[46] U. Pfahl, K. Fieweger, G. Adomeit, Self-ignition of diesel-relevant hydrocarbon-air mixtures under engine conditions, Symposium (International) on Combustion 26 (1996) 781789.

[47] D.F. Davidson, J.T. Herbon, D.C. Horning, R.K. Hanson, OH concentration time histories in n-alkane oxidation, International Journal of Chemical Kinetics 33 (2001) 775-783.

[48] S.S. Vasu, D.F. Davidson, Z. Hong, V. Vasudevan, R.K. Hanson, n-Dodecane oxidation at high-pressures: Measurements of ignition delay times and $\mathrm{OH}$ concentration time-histories, Proceedings of the Combustion Institute 32 (2009) 173-180.

[49] H.-P.S. Shen, J. Steinberg, J. Vanderover, M.A. Oehlschlaeger, A shock tube study of the ignition of n-heptane, $\mathrm{n}$-decane, n-dodecane, and n-tetradecane at elevated pressures, Energy \& Fuels 23 (2009) 2482-2489.

[50] D.F. Davidson, S.C. Ranganath, K.Y. Lam, M. Liaw, Z. Hong, R.K. Hanson, Ignition delay time measurements of normal alkanes and simple oxygenates, Journal of Propulsion and Power 26 (2010) 280-287. 
[51] T. Malewicki, K. Brezinsky, Experimental and modeling study on the pyrolysis and oxidation of n-decane and n-dodecane, Proceedings of the Combustion Institute 34 (2013) 361368.

[52] R. Minetti, M. Carlier, M. Ribaucour, E. Therssen, L.R. Sochet, A rapid compression machine investigation of oxidation and auto-ignition of $n$-Heptane: Measurements and modeling, Combustion and Flame 102 (1995) 298-309.

[53] K. Kumar, G. Mittal, C.-J. Sung, Autoignition of n-decane under elevated pressure and lowto-intermediate temperature conditions, Combustion and Flame 156 (2009) 1278-1288.

[54] D.M.A. Karwat, S.W. Wagnon, M.S. Wooldridge, C.K. Westbrook, Low-temperature speciation and chemical kinetic studies of n-heptane, Combustion and Flame 160 (2013) 26932706.

[55] H.J. Curran, P. Gaffuri, W.J. Pitz, C.K. Westbrook, A comprehensive modeling study of nheptane oxidation, Combustion and Flame 114 (1998) 149-177.

[56] E. Ranzi, A. Frassoldati, S. Granata, T. Faravelli, Wide-range kinetic modeling study of the pyrolysis, partial oxidation, and combustion of heavy n-alkanes, Industrial \& Engineering Chemistry Research 44 (2005) 5170-5183.

[57] C.K. Westbrook, W.J. Pitz, O. Herbinet, H.J. Curran, E.J. Silke, A comprehensive detailed chemical kinetic reaction mechanism for combustion of n-alkane hydrocarbons from n-octane to n-hexadecane, Combustion and Flame 156 (2009) 181-199.

[58] M. Chaos, F.L. Dryer, Chemical-kinetic modeling of ignition delay: Considerations in interpreting shock tube data, International Journal of Chemical Kinetics 42 (2010) 143-150. [59] G. Mittal, M.P. Raju, C.-J. Sung, CFD modeling of two-stage ignition in a rapid compression machine: Assessment of zero-dimensional approach, Combustion and Flame 157 (2010) 1316-1324.

[60] F.L. Dryer, F.M. Haas, J. Santner, T.I. Farouk, M. Chaos, Interpreting chemical kinetics from complex reaction-advection-diffusion systems: Modeling of flow reactors and related experiments, Progress in Energy and Combustion Science 44 (2014) 19-39.

[61] S.G. Davis, C.K. Law, Determination of and fuel structure effects on laminar flame speeds of C1 to C8 hydrocarbons, Combustion Science and Technology 140 (1998) 427-449.

[62] K. Kumar, C.-J. Sung, Laminar flame speeds and extinction limits of preheated ndecane/O2/N2 and n-dodecane/O2/N2 mixtures, Combustion and Flame 151 (2007) 209-224. [63] C. Ji, E. Dames, Y.L. Wang, H. Wang, F.N. Egolfopoulos, Propagation and extinction of premixed C5-C12 n-alkane flames, Combustion and Flame 157 (2010) 277-287.

[64] A.P. Kelley, A.J. Smallbone, D.L. Zhu, C.K. Law, Laminar flame speeds of C5 to C8 nalkanes at elevated pressures: Experimental determination, fuel similarity, and stretch sensitivity, Proceedings of the Combustion Institute 33 (2011) 963-970.

[65] H.H. Kim, S.H. Won, J. Santner, Z. Chen, Y. Ju, Measurements of the critical initiation radius and unsteady propagation of n-decane/air premixed flames, Proceedings of the Combustion Institute 34 (2013) 929-936.

[66] A.T. Holley, Y. Dong, M.G. Andac, F.N. Egolfopoulos, T. Edwards, Ignition and extinction of non-premixed flames of single-component liquid hydrocarbons, jet fuels, and their surrogates, Proceedings of the Combustion Institute 31 (2007) 1205-1213.

[67] S.H. Won, S. Dooley, F.L. Dryer, Y. Ju, A radical index for the determination of the chemical kinetic contribution to diffusion flame extinction of large hydrocarbon fuels, Combustion and Flame 159 (2012) 541-551. 
[68] R. Grana, K. Seshadri, A. Cuoci, U. Niemann, T. Faravelli, E. Ranzi, Kinetic modelling of extinction and autoignition of condensed hydrocarbon fuels in non-premixed flows with comparison to experiment, Combustion and Flame 159 (2012) 130-141.

[69] M. Foster, H. Pearlman, Cool flames at terrestrial, partial, and near-zero gravity, Combustion and Flame 147 (2006) 108-117.

[70] M. Foster, H. Pearlman, Cool flame propagation speeds, Combustion Science and Technology 179 (2007) 1349-1360.

[71] V. Nayagam, D.L. Dietrich, P.V. Ferkul, M.C. Hicks, F.A. Williams, Can cool flames support quasi-steady alkane droplet burning?, Combustion and Flame 159 (2012) 3583-3588. [72] T.I. Farouk, M.C. Hicks, F.L. Dryer, Multistage oscillatory "Cool Flame" behavior for isolated alkane droplet combustion in elevated pressure microgravity condition, Proceedings of the Combustion Institute 35 (2015) 1701-1708.

[73] V. Nayagam, D.L. Dietrich, M.C. Hicks, F.A. Williams, Cool-flame extinction during nalkane droplet combustion in microgravity, Combustion and Flame 162 (2015) 2140-2147. [74] T.I. Farouk, D. Dietrich, F.E. Alam, F.L. Dryer, Isolated n-decane droplet combustion Dual stage and single stage transition to "Cool Flame" droplet burning, Proceedings of the Combustion Institute 36 (2016) in press.

[75] S.H. Won, B. Jiang, P. Diévart, C.H. Sohn, Y. Ju, Self-sustaining n-heptane cool diffusion flames activated by ozone, Proceedings of the Combustion Institute 35 (2015) 881-888.

[76] C.H. Sohn, H.S. Han, C.B. Reuter, Y. Ju, S.H. Won, Thermo-kinetic dynamics of near-limit cool diffusion flames, Proceedings of the Combustion Institute 36 (2016) in press.

[77] C.B. Reuter, S.H. Won, Y. Ju, Flame structure and ignition limit of partially premixed cool flames in a counterflow burner, Proceedings of the Combustion Institute 36 (2016) in press.

[78] P. Zhao, C.K. Law, The role of global and detailed kinetics in the first-stage ignition delay in NTC-affected phenomena, Combustion and Flame 160 (2013) 2352-2358.

[79] S.H. Won, W. Sun, Y. Ju, Kinetic effects of toluene blending on the extinction limit of ndecane diffusion flames, Combustion and Flame 157 (2010) 411-420.

[80] S.H. Won, S. Dooley, F.L. Dryer, Y. Ju, Kinetic effects of aromatic molecular structures on diffusion flame extinction, Proceedings of the Combustion Institute 33 (2011) 1163-1170.

[81] J.K. Lefkowitz, S.H. Won, Y. Fenard, Y. Ju, Uncertainty assessment of species

measurements in acetone counterflow diffusion flames, Proceedings of the Combustion Institute 34 (2013) 813-820.

[82] T. Ombrello, S.H. Won, Y. Ju, S. Williams, Flame propagation enhancement by plasma excitation of oxygen. Part I: Effects of O3, Combustion and Flame 157 (2010) 1906-1915.

[83] K. Seshadri, F.A. Williams, Laminar flow between parallel plates with injection of a reactant at high reynolds number, International Journal of Heat and Mass Transfer 21 (1978) 251-253.

[84] J.E. Harrington, K.C. Smyth, Laser-induced fluorescence measurements of formaldehyde in a methane/air diffusion flame, Chemical Physics Letters 202 (1993) 196-202.

[85] A.E. Lutz, R.J. Kee, J.F. Grcar, F.M. Rupley, OPPDIF: A Fortran program for computing opposed-flow diffusion flames, Sandia National Laboratories Report SAND96-8243, 1997.

[86] S.M. Sarathy, C.K. Westbrook, M. Mehl, W.J. Pitz, C. Togbe, P. Dagaut, H. Wang, M.A.

Oehlschlaeger, U. Niemann, K. Seshadri, P.S. Veloo, C. Ji, F.N. Egolfopoulos, T. Lu,

Comprehensive chemical kinetic modeling of the oxidation of 2-methylalkanes from $\mathrm{C} 7$ to $\mathrm{C} 20$, Combustion and Flame 158 (2011) 2338-2357. 
[87] Y. Ju, W. Sun, M.P. Burke, X. Gou, Z. Chen, Multi-timescale modeling of ignition and flame regimes of n-heptane-air mixtures near spark assisted homogeneous charge compression ignition conditions, Proceedings of the Combustion Institute 33 (2011) 1245-1251.

[88] A. Stagni, A. Frassoldati, A. Cuoci, T. Faravelli, E. Ranzi, Skeletal mechanism reduction through species-targeted sensitivity analysis, Combustion and Flame 163 (2016) 382-393.

[89] H.J. Curran, P. Gaffuri, W.J. Pitz, C.K. Westbrook, A comprehensive modeling study of iso-octane oxidation, Combustion and Flame 129 (2002) 253-280.

[90] E. Ranzi, A. Frassoldati, R. Grana, A. Cuoci, T. Faravelli, A.P. Kelley, C.K. Law, Hierarchical and comparative kinetic modeling of laminar flame speeds of hydrocarbon and oxygenated fuels, Progress in Energy and Combustion Science 38 (2012) 468-501.

[91] Z. Luo, S. Som, S.M. Sarathy, M. Plomer, W.J. Pitz, D.E. Longman, T. Lu, Development and validation of an $\mathrm{n}$-dodecane skeletal mechanism for spray combustion applications, Combustion Theory and Modelling 18 (2014) 187-203.

[92] A. Frassoldati, G. D'Errico, T. Lucchini, A. Stagni, A. Cuoci, T. Faravelli, A. Onorati, E. Ranzi, Reduced kinetic mechanisms of diesel fuel surrogate for engine CFD simulations, Combustion and Flame 162 (2015) 3991-4007.

[93] H. Wang, Y. Ra, M. Jia, R.D. Reitz, Development of a reduced n-dodecane-PAH mechanism and its application for n-dodecane soot predictions, Fuel 136 (2014) 25-36. [94] Y. Ra, R.D. Reitz, A combustion model for multi-component fuels using a physical surrogate group chemistry representation (PSGCR), Combustion and Flame 162 (2015) 34563481.

[95] W. Sun, Z. Chen, X. Gou, Y. Ju, A path flux analysis method for the reduction of detailed chemical kinetic mechanisms, Combustion and Flame 157 (2010) 1298-1307. [96] Y. Ju, W. Sun, Plasma assisted combustion: Dynamics and chemistry, Progress in Energy and Combustion Science 48 (2015) 21-83.

[97] W. Sun, S.H. Won, T. Ombrello, C. Carter, Y. Ju, Direct ignition and S-curve transition by in situ nano-second pulsed discharge in methane/oxygen/helium counterflow flame, Proceedings of the Combustion Institute 34 (2013) 847-855.

[98] V.R. Katta, W.M. Roquemore, Formation of a cool diffusion flame and its characteristics, Proceedings of the Combustion Institute 36 (2016) in press.

[99] D.J.M. Ray, R. Ruiz Diaz, D.J. Waddington, Gas-phase oxidation of butene-2: The role of acetaldehyde in the reaction, Symposium (International) on Combustion 14 (1973) 259-266. [100] T. Lu, C.K. Law, A directed relation graph method for mechanism reduction, Proceedings of the Combustion Institute 30 (2005) 1333-1341.

[101] A. Stagni, A. Cuoci, A. Frassoldati, T. Faravelli, E. Ranzi, Lumping and Reduction of Detailed Kinetic Schemes: an Effective Coupling, Industrial \& Engineering Chemistry Research 53 (2014) 9004-9016. 


\section{Figure Captions}

Fig. 1. A schematic of the experimental counterflow burner setup for producing cool diffusion flames, including the ozone generator and $\mathrm{CH}_{2} \mathrm{O}$ PLIF system.

Fig. 2. Direct photographs of $n$-dodecane cool diffusion flames with and without ozone addition at a fuel mass fraction $Y_{F}=0.374$ and a global strain rate of $a=68 \mathrm{~s}^{-1}$. The exposure time for both photographs is one second, and the images shown here have been enhanced in brightness by $50 \%$. The ozone concentrations in the oxidizer are (a) $3.6 \%$ and (b) $0 \%$.

Fig. 3. Raw $\mathrm{CH}_{2} \mathrm{O}$ PLIF images of $n$-dodecane cool diffusion flames with and without ozone addition at a fuel mass fraction $Y_{F}=0.374$ and a global strain rate of $a=68 \mathrm{~s}^{-1}$. The ozone concentrations in the oxidizer are (a) $3.6 \%$ and (b) $0 \%$.

Fig. 4. Measured extinction limits of $n$-alkane cool diffusion flames with ozone addition as a function of fuel mass fraction. The ozone concentration varies with the flow rate of oxidizer.

Fig. 5. Measured extinction limits of $n$-alkane cool diffusion flames without ozone addition as a function of fuel mass fraction.

Fig. 6. Rate constant sensitivity analysis for the extinction strain rates of $n$-heptane cool diffusion flames with and without ozone addition. A reduced version (131 species) of the detailed NUI $n$ heptane model [44] is used.

Table 1. Summary of the reduced models (PFA method) employed in calculating the extinction strain rates of the $n$-alkane diffusion flames in Fig. 7.

Fig. 7. Comparison between the experimentally measured and numerically predicted extinction limits for $n$-alkane flames.

Table 2. Summary of the reduced models (PFA method) employed in calculating the extinction strain rates of the $n$-dodecane and $n$-heptane diffusion flames in Fig. 8.

Fig. 8. Effect of model reduction on the numerically predicted extinction limits for (a) $n$ dodecane and (b) $n$-heptane flames.

Fig. 9. Effect of model reduction on the numerically predicted ignition delay times for (a) $n$ dodecane and (b) $n$-heptane mixtures in a closed homogeneous reactor. 
Fig. 10. Effect of model reduction on the numerically predicted heat release rate distribution for $n$-heptane (a) hot flames and (b) cool flames.

Table 3. List of the top $10 n$-heptane cool flame heat production and heat consumption reactions.

Table 4. Summary of the reduced models chosen from the literature in calculating the extinction strain rates of the $n$-dodecane and $n$-heptane diffusion flames in Fig. 11.

Fig. 11. Comparison between experimentally measured and numerically predicted extinction limits for (a) $n$-dodecane and (b) $n$-heptane flames. 


\section{Figure Captions}

Fig. 1. A schematic of the experimental counterflow burner setup for producing cool diffusion flames, including the ozone generator and $\mathrm{CH}_{2} \mathrm{O}$ PLIF system.

Fig. 2. Direct photographs of $n$-dodecane cool diffusion flames with and without ozone addition at a fuel mass fraction $Y_{F}=0.374$ and a global strain rate of $a=68 \mathrm{~s}^{-1}$. The exposure time for both photographs is one second, and the images shown here have been enhanced in brightness by $50 \%$. The ozone concentrations in the oxidizer are (a) $3.6 \%$ and (b) $0 \%$.

Fig. 3. Raw $\mathrm{CH}_{2} \mathrm{O}$ PLIF images of $n$-dodecane cool diffusion flames with and without ozone addition at a fuel mass fraction $Y_{F}=0.374$ and a global strain rate of $a=68 \mathrm{~s}^{-1}$. The ozone concentrations in the oxidizer are (a) $3.6 \%$ and (b) $0 \%$.

Fig. 4. Measured extinction limits of $n$-alkane cool diffusion flames with ozone addition as a function of fuel mass fraction. The ozone concentration varies with the flow rate of oxidizer.

Fig. 5. Measured extinction limits of $n$-alkane cool diffusion flames without ozone addition as a function of fuel mass fraction.

Fig. 6. Rate constant sensitivity analysis for the extinction strain rates of $n$-heptane cool diffusion flames with and without ozone addition. A reduced version (131 species) of the detailed NUI $n$ heptane model [44] is used.

Table 1. Summary of the reduced models (PFA method) employed in calculating the extinction strain rates of the $n$-alkane diffusion flames in Fig. 7.

Fig. 7. Comparison between the experimentally measured and numerically predicted extinction limits for $n$-alkane flames.

Table 2. Summary of the reduced models (PFA method) employed in calculating the extinction strain rates of the $n$-dodecane and $n$-heptane diffusion flames in Fig. 8.

Fig. 8. Effect of model reduction on the numerically predicted extinction limits for (a) $n$ dodecane and (b) $n$-heptane flames.

Fig. 9. Effect of model reduction on the numerically predicted ignition delay times for (a) $n$ dodecane and (b) $n$-heptane mixtures in a closed homogeneous reactor. 
Fig. 10. Effect of model reduction on the numerically predicted heat release rate distribution for n-heptane (a) hot flames and (b) cool flames.

Table 3. List of the top $10 n$-heptane cool flame heat production and heat consumption reactions.

Table 4. Summary of the reduced models chosen from the literature in calculating the extinction strain rates of the $n$-dodecane and $n$-heptane diffusion flames in Fig. 11.

Fig. 11. Comparison between experimentally measured and numerically predicted extinction limits for (a) $n$-dodecane and (b) $n$-heptane flames. 
Fig. 1. A schematic of the experimental counterflow burner setup for producing cool diffusion flames, including the ozone generator and $\mathrm{CH}_{2} \mathrm{O}$ PLIF system.

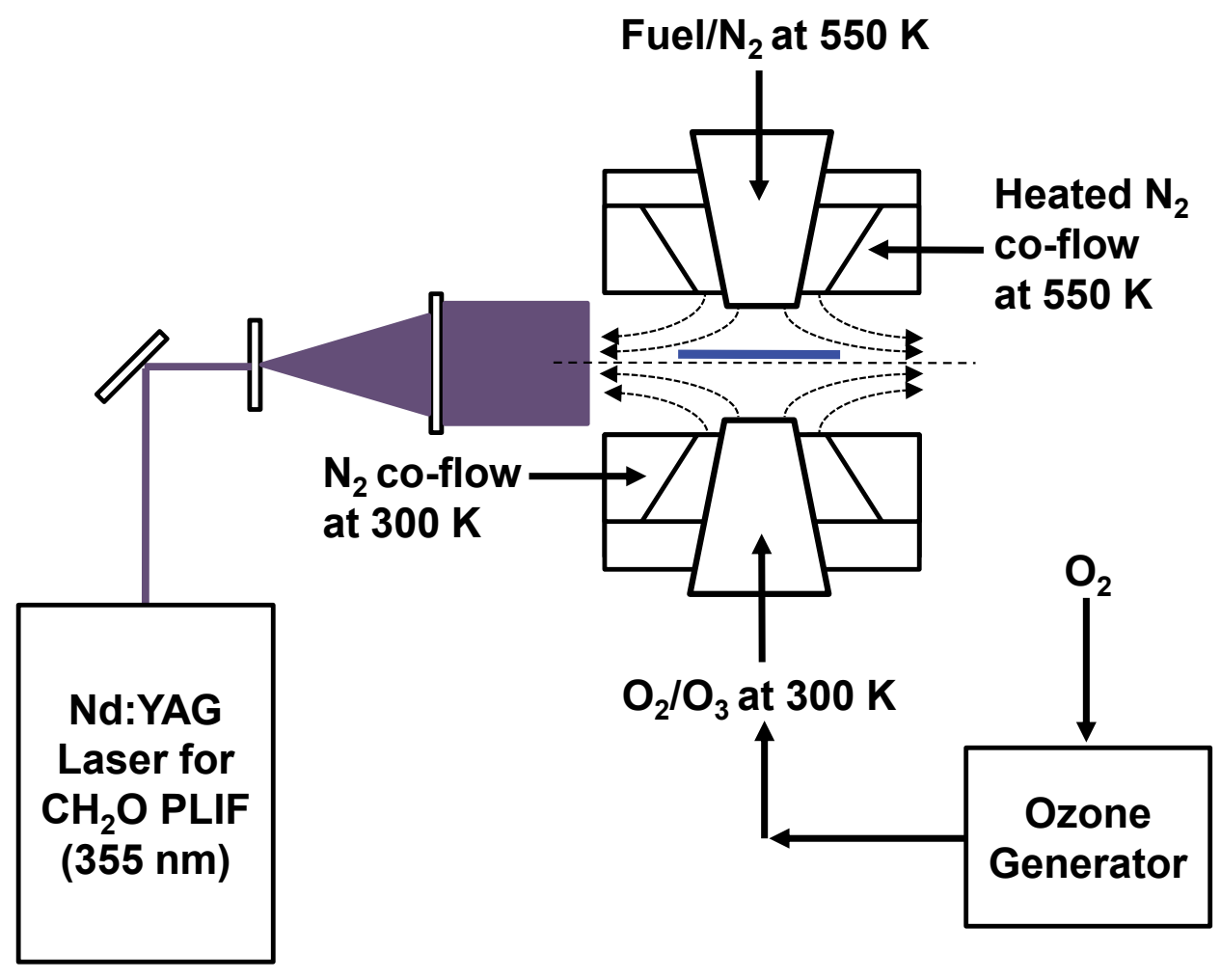


Fig. 2. Direct photographs of $n$-dodecane cool diffusion flames with and without ozone addition at a fuel mass fraction $Y_{F}=0.374$ and a global strain rate of $a=68 \mathrm{~s}^{-1}$. The exposure time for both photographs is one second, and the images shown here have been enhanced in brightness by $50 \%$. The ozone concentrations in the oxidizer are (a) $3.6 \%$ and (b) $0 \%$.

(a)

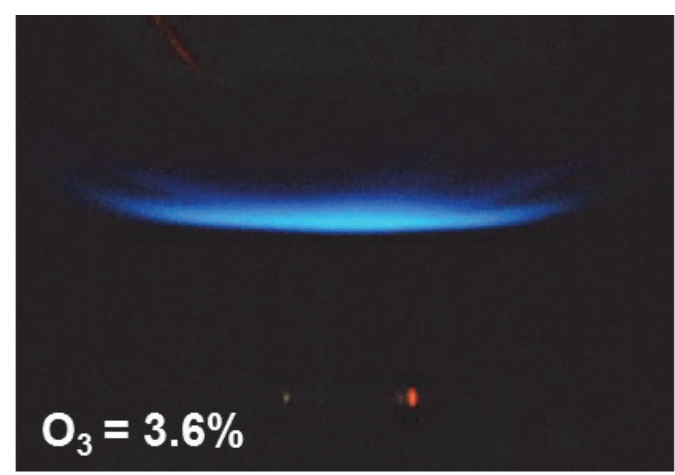

(b)

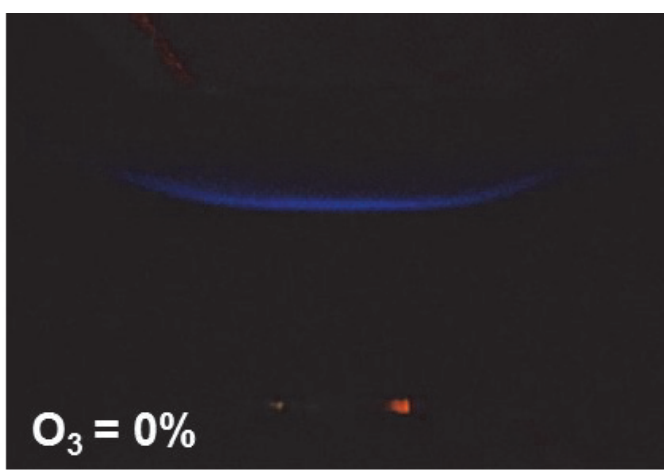


Fig. 3. Raw $\mathrm{CH}_{2} \mathrm{O}$ PLIF images of $n$-dodecane cool diffusion flames with and without ozone addition at a fuel mass fraction $Y_{F}=0.374$ and a global strain rate of $a=68 \mathrm{~s}^{-1}$. The ozone concentrations in the oxidizer are (a) $3.6 \%$ and (b) $0 \%$.

(a)

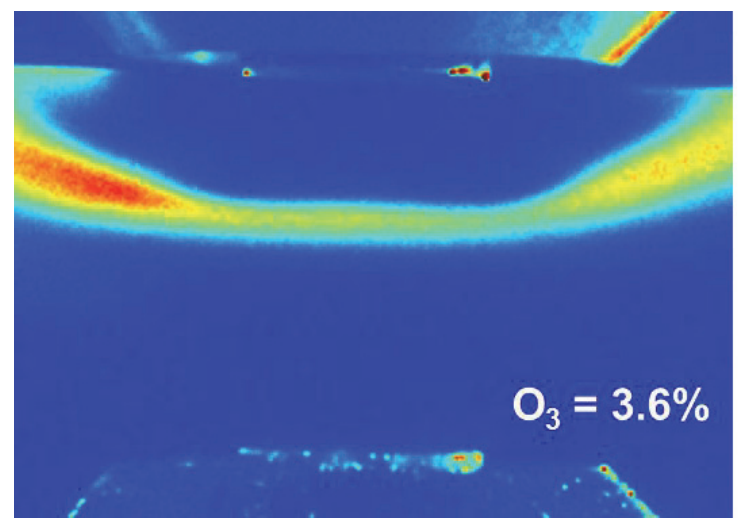

(b)

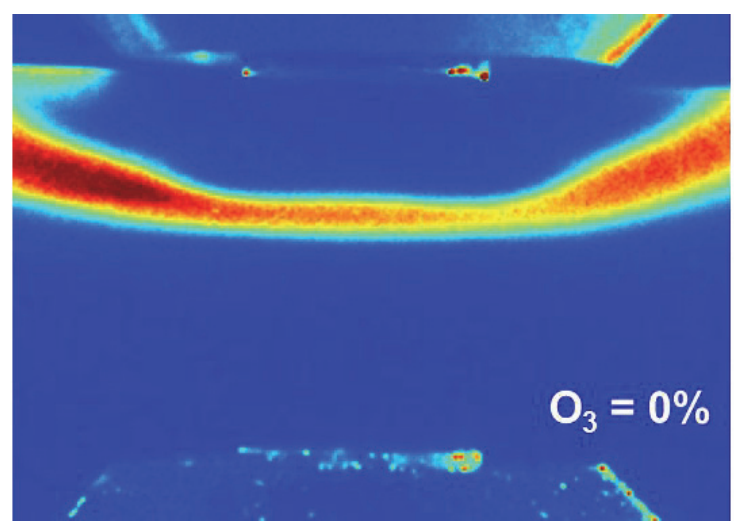


Fig. 4. Measured extinction limits of $n$-alkane cool diffusion flames with ozone addition as a function of fuel mass fraction. The ozone concentration varies with the flow rate of oxidizer.

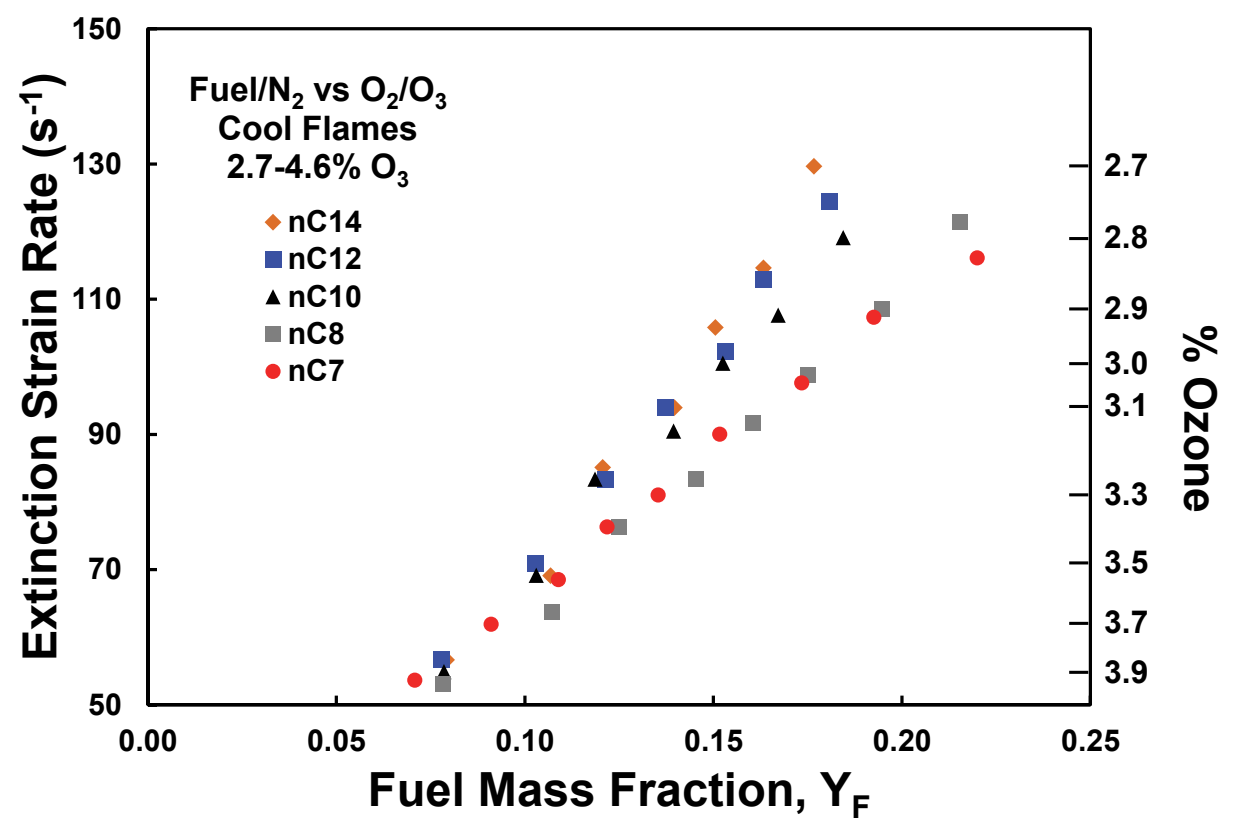


Fig. 5. Measured extinction limits of $n$-alkane cool diffusion flames without ozone addition as a function of fuel mass fraction.

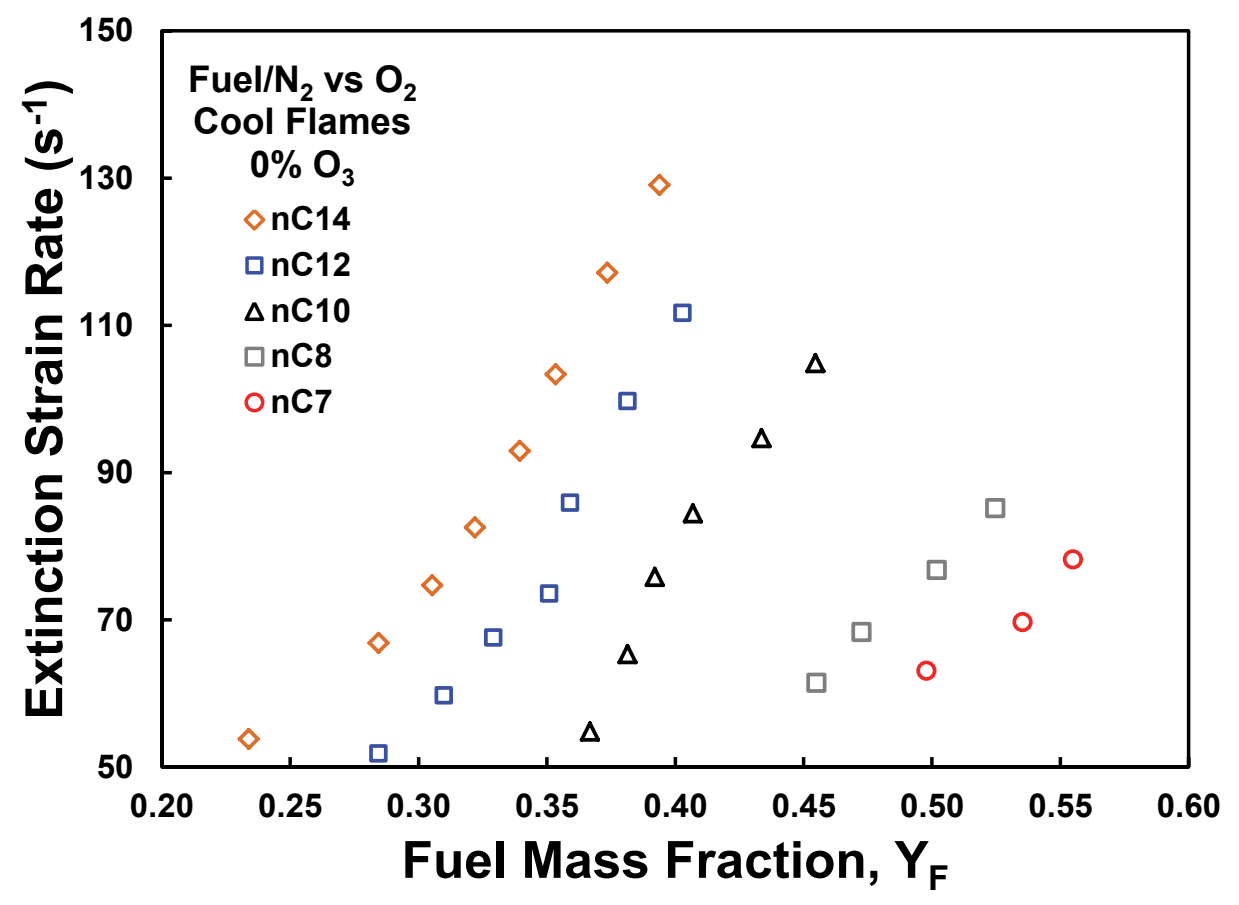


Fig. 6. Rate constant sensitivity analysis for the extinction strain rates of $n$-heptane cool diffusion flames with and without ozone addition. A reduced version (131 species) of the detailed NUI $n$ heptane model [44] is used.

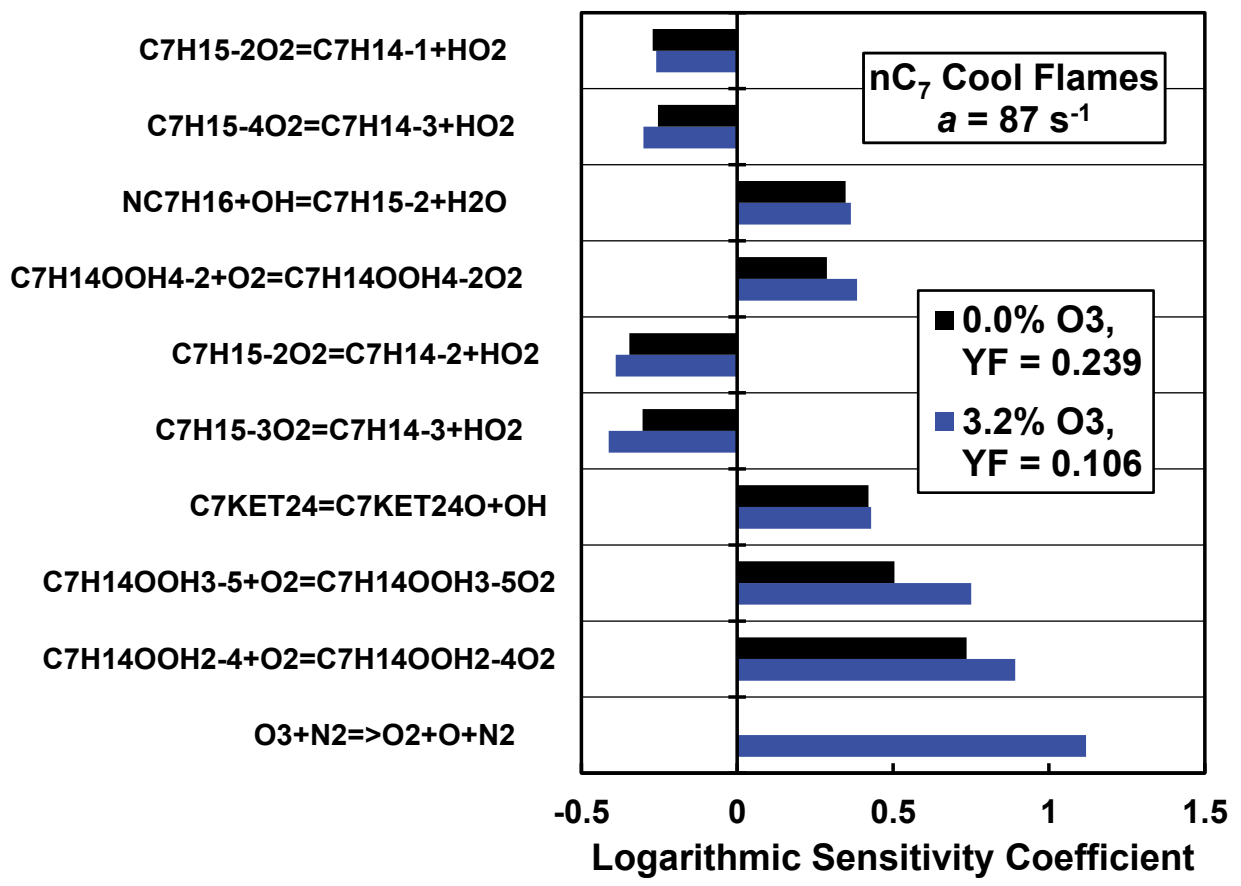


Fig. 7. Comparison between the experimentally measured and numerically predicted extinction limits for $n$-alkane flames.

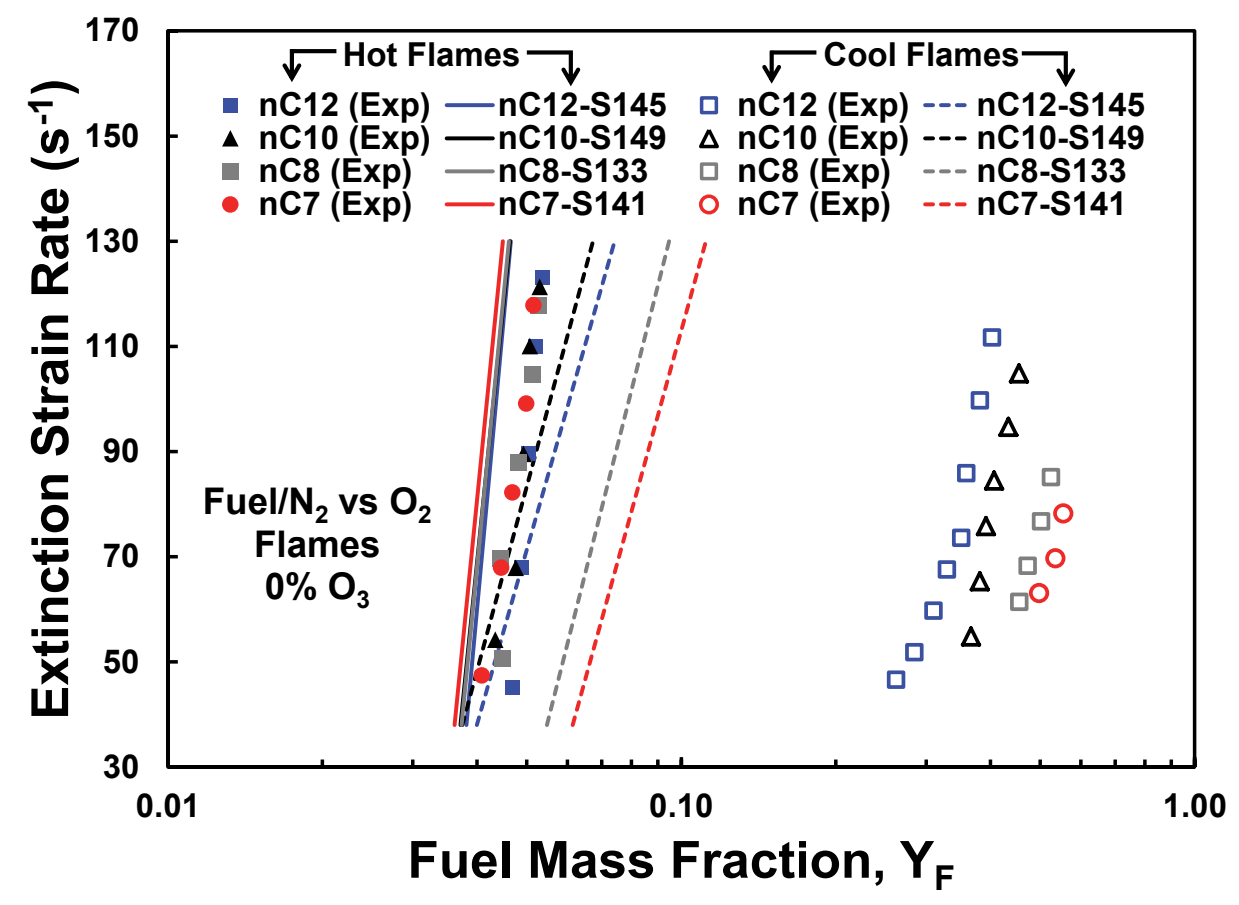


Fig. 8. Effect of model reduction on the numerically predicted extinction limits for (a) $n$ dodecane and (b) $n$-heptane flames.

(a)

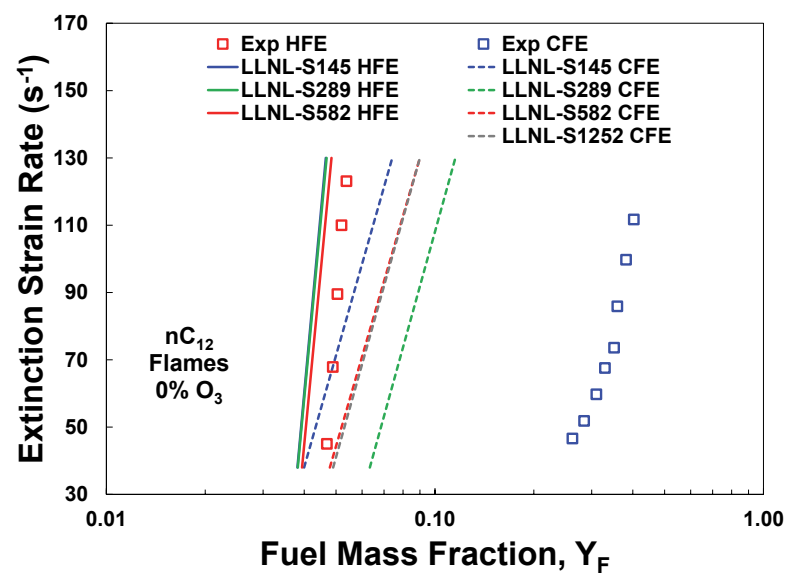

(b)

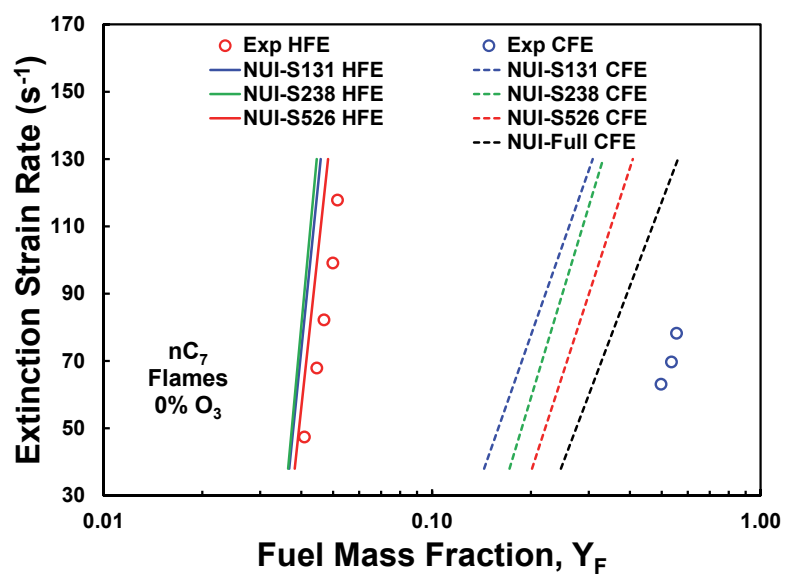


Fig. 9. Effect of model reduction on the numerically predicted ignition delay times for (a) $n$ dodecane and (b) $n$-heptane mixtures in a closed homogeneous reactor.

(a)

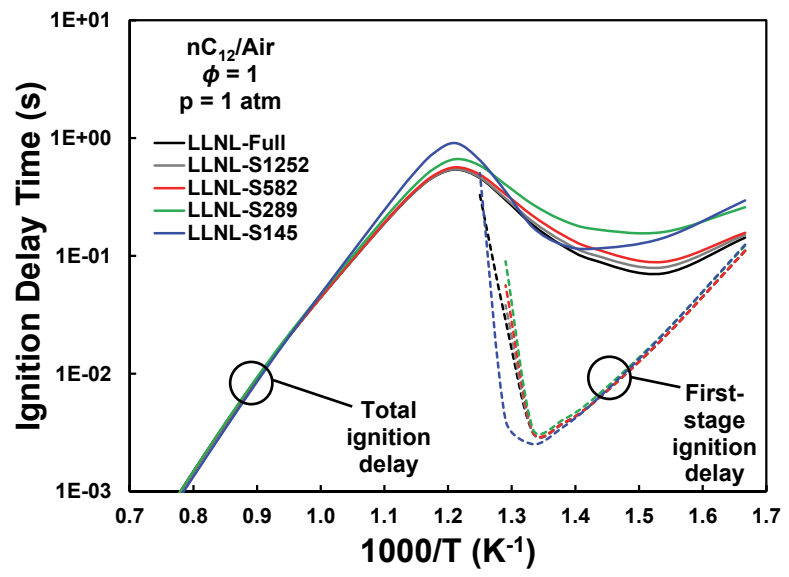

(b)

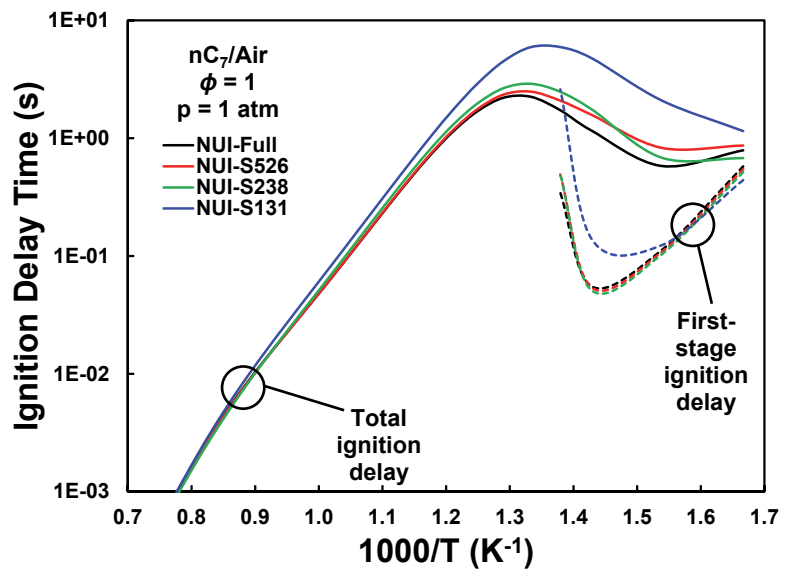


Fig. 10. Effect of model reduction on the numerically predicted heat release rate distribution for n-heptane (a) hot flames and (b) cool flames.

(a)

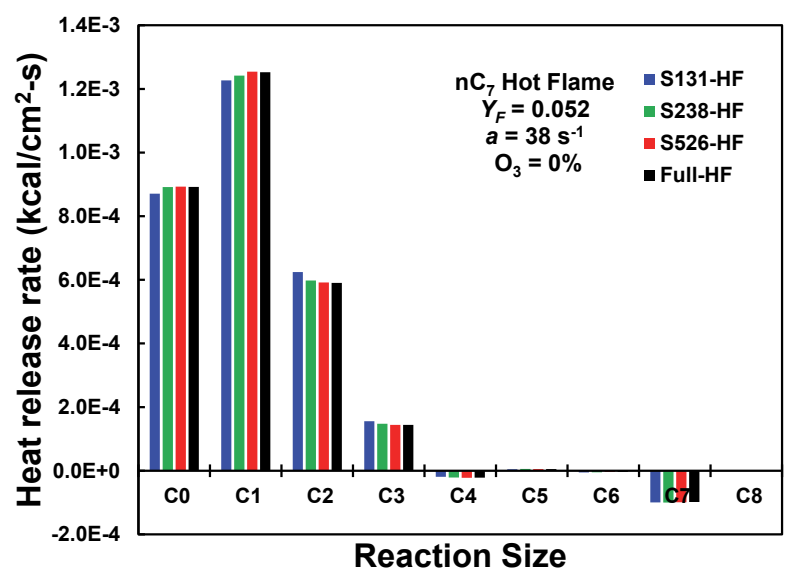

(b)

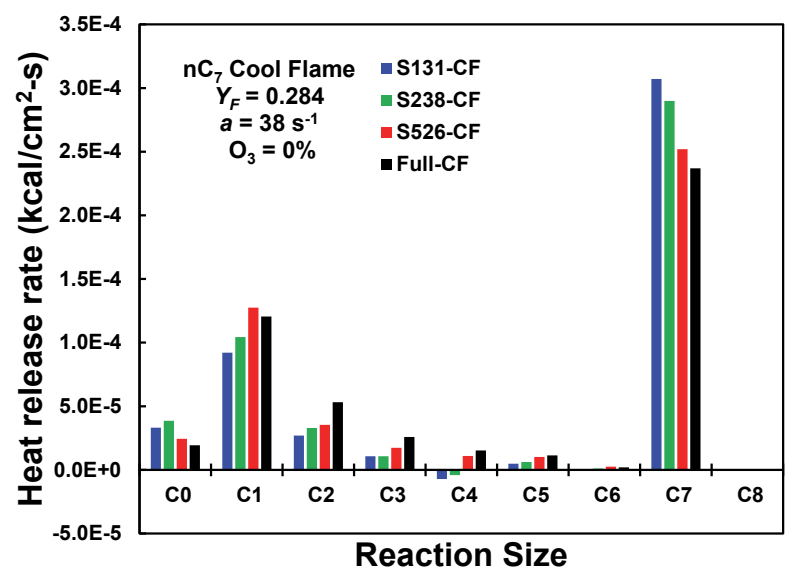


Fig. 11. Comparison between experimentally measured and numerically predicted extinction limits for (a) $n$-dodecane and (b) $n$-heptane flames.

(a)

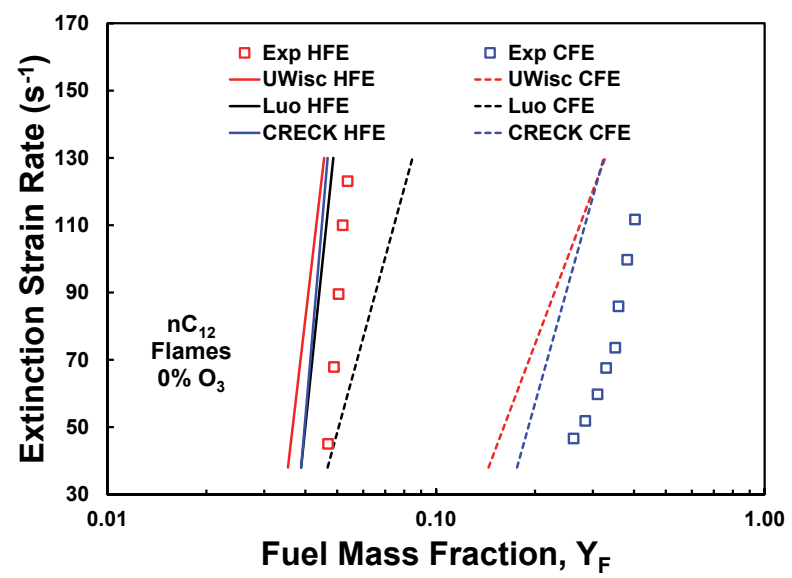

(b)

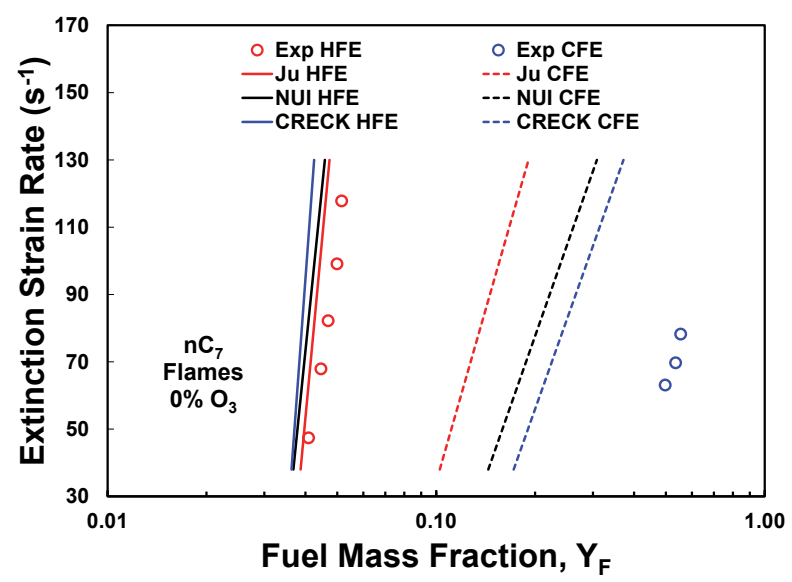


Table 1. Summary of the reduced models (PFA method) employed in calculating the extinction strain rates of the $n$-alkane diffusion flames in Fig. 7.

\begin{tabular}{|c|c|c|c|c|c|}
\hline $\mathbf{n C}_{\#}$ & Species & Reactions & Base Model & PFA Threshold & $\mathbf{C}_{\#}$ Species \\
\hline $\mathrm{nC}_{7}$ & 141 & 696 & LLNL (2011) [86] & 0.30 & 48 \\
\hline $\mathrm{nC}_{8}$ & 133 & 651 & LLNL (2011) [86] & 0.30 & 43 \\
\hline $\mathrm{nC}_{10}$ & 149 & 636 & LLNL (2011)[86] & 0.30 & 40 \\
\hline $\mathrm{nC}_{12}$ & 145 & 648 & LLNL (2011)[86] & 0.32 & 25 \\
\hline
\end{tabular}


Table 2. Summary of the reduced models (PFA method) employed in calculating the extinction strain rates of the $n$-dodecane and $n$-heptane diffusion flames in Fig. 8.

\begin{tabular}{|c|c|c|c|c|}
\hline $\mathbf{n C}_{\mathbf{1 2}}$ Model & Species & Reactions & PFA Threshold & $\mathbf{C}_{\mathbf{1 2}}$ Species \\
\hline LLNL & 145 & 648 & 0.32 & 25 \\
\hline LLNL & 289 & 1459 & 0.20 & 75 \\
\hline LLNL & 582 & 2609 & 0.10 & 127 \\
\hline LLNL & 1252 & 5477 & 0.05 & 169 \\
\hline LLNL & 2755 & 11173 & $---[86]$ & 474 \\
\hline \multicolumn{5}{|c|}{} \\
\hline nC $\mathbf{7}_{7}$ Model & Species & Reactions & PFA Threshold & C $_{7}$ Species \\
\hline NUI & 131 & 792 & 0.35 & 41 \\
\hline NUI & 238 & 1259 & 0.25 & 82 \\
\hline NUI & 526 & 2720 & 0.10 & 140 \\
\hline NUI & 1268 & 5336 & $---[44]$ & 258 \\
\hline
\end{tabular}


Table 3. List of the top $10 n$-heptane cool flame heat production and heat consumption reactions.

\begin{tabular}{|c|c|c|c|}
\hline Size & Reaction & \% of Heat Production & Models \\
\hline $\mathrm{C}_{7}$ & $\mathrm{C} 7 \mathrm{H} 15-2+\mathrm{O} 2=\mathrm{C} 7 \mathrm{H} 15-2 \mathrm{O} 2$ & 6.8 & Full, 526, 238, 131 \\
\hline $\mathrm{C}_{7}$ & $\mathrm{C} 7 \mathrm{H} 15-3+\mathrm{O} 2=\mathrm{C} 7 \mathrm{H} 15-3 \mathrm{O} 2$ & 5.2 & Full, 526, 238, 131 \\
\hline $\mathrm{C}_{1}$ & $\mathrm{CH} 3+\mathrm{O} 2(+\mathrm{M})=\mathrm{CH} 3 \mathrm{O} 2(+\mathrm{M})$ & 4.3 & Full, 526, 238, 131 \\
\hline $\mathrm{C}_{7}$ & $\mathrm{NC} 7 \mathrm{H} 16+\mathrm{OH}=\mathrm{C} 7 \mathrm{H} 15-2+\mathrm{H} 2 \mathrm{O}$ & 4.1 & Full, 526, 238, 131 \\
\hline $\mathrm{C}_{1}$ & $\mathrm{CH} 3 \mathrm{OH}+\mathrm{O} 2=\mathrm{CH} 3 \mathrm{O}+\mathrm{HO} 2$ & 3.9 & Full, 526 \\
\hline $\mathrm{C}_{7}$ & $\mathrm{C} 7 \mathrm{H} 15-4+\mathrm{O} 2=\mathrm{C} 7 \mathrm{H} 15-4 \mathrm{O} 2$ & 3.7 & Full, 526, 238, 131 \\
\hline $\mathrm{C}_{1}$ & $\mathrm{HCO}+\mathrm{O} 2=\mathrm{CO}+\mathrm{HO} 2$ & 3.3 & Full, 526, 238, 131 \\
\hline $\mathrm{C}_{7}$ & $\mathrm{NC} 7 \mathrm{H} 16+\mathrm{OH}=\mathrm{C} 7 \mathrm{H} 15-3+\mathrm{H} 2 \mathrm{O}$ & 3.1 & Full, 526, 238, 131 \\
\hline $\mathrm{C}_{7}$ & $\mathrm{C} 7 \mathrm{H} 15-1+\mathrm{O} 2=\mathrm{C} 7 \mathrm{H} 15-1 \mathrm{O} 2$ & 3.1 & Full, 526, 238, 131 \\
\hline $\mathrm{C}_{2}$ & $\mathrm{C} 2 \mathrm{H} 5+\mathrm{O} 2=\mathrm{C} 2 \mathrm{H} 5 \mathrm{O} 2$ & 3.0 & Full, 526, 238 \\
\hline Size & Reaction & $\%$ of Heat Consumption & Models \\
\hline $\mathrm{C}_{7}$ & $\mathrm{C} 7 \mathrm{KET} 42=\mathrm{C} 7 \mathrm{KET} 42 \mathrm{O}+\mathrm{OH}$ & 5.5 & Full, 526, 238, 131 \\
\hline $\mathrm{C}_{7}$ & $\mathrm{C} 7 \mathrm{KET} 24=\mathrm{C} 7 \mathrm{KET} 24 \mathrm{O}+\mathrm{OH}$ & 5.1 & Full, 526, 238, 131 \\
\hline $\mathrm{C}_{7}$ & $\mathrm{C} 7 \mathrm{KET} 35=\mathrm{C} 7 \mathrm{KET} 35 \mathrm{O}+\mathrm{OH}$ & 3.6 & Full, 526, 238, 131 \\
\hline $\mathrm{C}_{7}$ & $\mathrm{C} 7 \mathrm{H} 15-3 \mathrm{O}=\mathrm{NC} 3 \mathrm{H} 7+\mathrm{CH} 3 \mathrm{CO}+\mathrm{C} 2 \mathrm{H} 5$ & 2.9 & Full, 526 \\
\hline $\mathrm{C}_{7}$ & $\mathrm{C} 7 \mathrm{H} 15-2 \mathrm{O} 2=\mathrm{C} 7 \mathrm{H} 14 \mathrm{OOH} 2-5$ & 2.7 & Full, 526, 238 \\
\hline $\mathrm{C}_{7}$ & $\mathrm{C} 7 \mathrm{H} 15-4 \mathrm{O} 2=\mathrm{C} 7 \mathrm{H} 14 \mathrm{OOH} 4-2$ & 2.4 & Full, 526, 238, 131 \\
\hline $\mathrm{C}_{2}$ & $\mathrm{CH} 3 \mathrm{CO}(+\mathrm{M})=\mathrm{CH} 3+\mathrm{CO}(+\mathrm{M})$ & 2.4 & Full, 526, 238, 131 \\
\hline $\mathrm{C}_{7}$ & $\mathrm{C} 7 \mathrm{H} 15-4 \mathrm{O}=\mathrm{HCO}+\mathrm{NC} 3 \mathrm{H} 7+\mathrm{NC} 3 \mathrm{H} 7$ & 2.4 & Full \\
\hline $\mathrm{C}_{1}$ & $\mathrm{CH} 3 \mathrm{O} 2 \mathrm{H}=\mathrm{CH} 3 \mathrm{O}+\mathrm{OH}$ & 2.3 & Full, 526, 238, 131 \\
\hline $\mathrm{C}_{7}$ & $\mathrm{C} 7 \mathrm{H} 15-2 \mathrm{O} 2=\mathrm{C} 7 \mathrm{H} 14 \mathrm{OOH} 2-4$ & 2.2 & Full, 526, 238, 131 \\
\hline
\end{tabular}


Table 4. Summary of the reduced models chosen from the literature in calculating the extinction strain rates of the $n$-dodecane and $n$-heptane diffusion flames in Fig. 11.

\begin{tabular}{|c|c|c|c|c|c|}
\hline Reduced nC $\mathbf{1 2}_{\mathbf{1 2}}$ Model & Species & Reactions & Base Model & Base Type & C $_{\mathbf{1 2}}$ Species \\
\hline Luo [91] & 105 & 420 & LLNL [86] & Detailed & 25 \\
\hline CRECK [92] & 96 & 892 & CRECK [90] & Lumped & 6 \\
\hline UWisc [93] & 100 & 432 & UWisc [94] & Lumped & 5 \\
\hline \multicolumn{7}{|l|}{} \\
\hline Reduced nC Model $_{\mathbf{7}}$ Mecies & Reactions & Base Model & Base Type & C $_{\mathbf{7}}$ Species \\
\hline Ju [87] & 128 & 565 & LLNL [89] & Detailed & 41 \\
\hline CRECK [88] & 115 & 856 & CRECK [90] & Lumped & 15 \\
\hline NUI & 131 & 792 & NUI [44] & Detailed & 41 \\
\hline
\end{tabular}

